\title{
Guillain-Barré syndrome spectrum associated with COVID-19: an up-to-date systematic review of 73 cases
}

\author{
Samir Abu-Rumeileh ${ }^{1} \cdot$ Ahmed Abdelhak $^{1,2,3} \cdot$ Matteo Foschi $^{4} \cdot$ Hayrettin Tumani $^{1,5} \cdot$ Markus Otto $^{1}$ (i)
}

Received: 14 June 2020 / Revised: 22 July 2020 / Accepted: 27 July 2020 / Published online: 25 August 2020

(c) The Author(s) 2020

\begin{abstract}
Since coronavirus disease-2019 (COVID-19) outbreak in January 2020, several pieces of evidence suggested an association between the spectrum of Guillain-Barré syndrome (GBS) and severe acute respiratory syndrome coronavirus-2 (SARS$\mathrm{CoV}-2)$. Most findings were reported in the form of case reports or case series, whereas a comprehensive overview is still lacking. We conducted a systematic review and searched for all published cases until July 20th 2020 . We included 73 patients reported in 52 publications. A broad age range was affected (mean 55, min 11-max 94 years) with male predominance (68.5\%). Most patients showed respiratory and/or systemic symptoms, and developed GBS manifestations after COVID-19. However, asymptomatic cases for COVID-19 were also described. The distributions of clinical variants and electrophysiological subtypes resemble those of classic GBS, with a higher prevalence of the classic sensorimotor form and the acute inflammatory demyelinating polyneuropathy, although rare variants like Miller Fisher syndrome were also reported. Cerebrospinal fluid (CSF) albuminocytological dissociation was present in around 71\% cases, and CSF SARS-CoV-2 RNA was absent in all tested cases. More than $70 \%$ of patients showed a good prognosis, mostly after treatment with intravenous immunoglobulin. Patients with less favorable outcome were associated with a significantly older age in accordance with previous findings regarding both classic GBS and COVID-19. COVID-19-associated GBS seems to share most features of classic post-infectious GBS and possibly the same immune-mediated pathogenetic mechanisms. Nevertheless, more extensive epidemiological studies are needed to clarify these issues.
\end{abstract}

Keywords COVID-19 · SARS-CoV-2 · Coronavirus · Guillain-Barré syndrome · Miller Fisher syndrome · Neurology · Autoimmune $\cdot$ Polyradiculopathy $\cdot$ Neuroimmunology

\section{Introduction}

Coronavirus disease 2019 (COVID-19) pandemic has rapidly spread around the world from Jan-2020, with more than $14,000,000$ cases confirmed so far [1]. Although primary

Markus Otto

markus.otto@uni-ulm.de

1 Department of Neurology, Ulm University Hospital, 89070 Ulm, Germany

2 Department of Neurology and Stroke, University Hospital of Tübingen, 72076 Tübingen, Germany

3 Hertie Institute of Clinical Brain Research, University of Tübingen, 72076 Tübingen, Germany

4 Neurology Unit, S. Maria delle Croci Hospital-AUSL Romagna, ambito di Ravenna, 48121 Ravenna, Italy

5 Specialty Hospital of Neurology Dietenbronn, 88477 Schwendi, Germany affecting the respiratory system, central and peripheral neurological manifestations associated with severe acute respiratory syndrome coronavirus 2 (SARS-CoV-2) infection have been increasingly reported [2-4]. In detail, several pieces of evidence suggested an association between SARS-CoV-2 infection and the development of Guillain-Barré Syndrome (GBS) [5-56].

GBS represents the most common cause of acute flaccid paralysis [57]. The classic form is an immune-mediated acute-onset demyelinating polyradiculoneuropathy (acute inflammatory demyelinating polyneuropathy-AIDP) typically presenting with ascending weakness, loss of deep tendon reflexes, and sensory deficits. Diagnosis of GBS relies on the results of clinical, electrophysiological, and cerebrospinal fluid (CSF) examinations (classically albuminocytological dissociation) [57-59]. The clinical spectrum of GBS encompasses a classic sensorimotor form, Miller Fisher syndrome (MFS), bilateral facial palsy with paraesthesia, pure 
motor, pure sensory, paraparetic, pharyngeal-cervical-brachial variants, polyneuritis cranialis (GBS-MFS overlap), and Bickerstaff brainstem encephalitis [57-60]. As regard electrophysiological features, three main subtypes are recognized: AIDP, acute motor axonal neuropathy (AMAN), and acute motor sensory axonal neuropathy (AMSAN) [57, $58,61]$. Peripheral nerve damage is thought to be provoked by an aberrant immune response to infections, in some cases driven by the production of autoreactive antibodies (anti-ganglioside antibodies) [57-59]. Potential triggering pathogens include both viruses [e.g., cytomegalovirus (CMV), Epstein-Barr virus (EBV), influenza virus, hepatitis E virus, and Zika virus] and bacteria (e.g., Campylobacter Jejuni, Mycoplasma Pneumoniae) [57, 58, 62]. However, a relationship with other events has been also described (e.g., vaccinations, surgery, administration of checkpoint inhibitors, and malignancy) [57, 58]. Given that a potential causal association with beta-coronaviruses [Middle East Respiratory Syndrome (MERS-CoV)] has already been speculated, the relationship between COVID-19 and GBS deserves undoubtedly further attention [63, 64].

With this background, our systematic review aimed to provide a comprehensive and updated overview of all case reports and series of COVID-19-related GBS to identify predominant clinical, laboratory, and neurophysiological patterns and to discuss the possible underlying pathophysiology.

\section{Methods}

We performed a systematic review according to the SALSA (Search, Appraisal, Synthesis, and Analysis) analytic framework [65]. We screened in PubMed and Google Scholar databases for all case descriptions of GBS associated with COVID-19 that were published from January 1st 2020 up to July 20th 2020. Keywords (including all commonly used abbreviations of these terms) used in the search strategy were as follows: ["acute autoimmune neuropathy" OR "acute inflammatory demyelinating polyneuropathy" OR "acute inflammatory demyelinating polyradiculoneuropathy," OR "acute inflammatory polyneuropathy" OR "Demyelinating Polyradiculoneuropathy" OR "Guillain-Barre Syndrome" OR "Guillain-Barre" OR ““'Miller-Fisher" OR "Bickerstaff encephalitis" OR "AIDP" OR "AMAN" OR "AMSAN" OR polyneuritis cranialis] AND ["COVID-19" OR "Wuhan coronavirus" OR "novel coronavirus" OR "novel coronavirus 2019" OR "SARS" OR "SARS-CoV-2"]. Suitable references were also identified in the authors' archives of scientific literature on GBS. We restricted our search to studies published in English, Spanish, or Italian. Publications that were not peer-reviewed were excluded from this study. PRISMA criteria were applied. For each case, we extracted data concerning demographic and clinical variables, results of diagnostic investigations, and outcome. If the GBS clinical variant [57] or the electrophysiological subtype [61] was not explicitly reported in the paper, we reconstructed it, when possible, from reported details. We also classified the diagnostic certainty of all cases according to the Brighton Criteria [66]. Searches were performed by SAR, AA, and MF. The selection of relevant articles was shared with all authors.

For statistical analysis, we used IBM SPSS Statistics version 21 (IBM, Armonk, NY, USA). Based on the distribution of values, continuous data were expressed as mean \pm standard deviation or as median and interquartile range (IQR). Depending on the number of groups and data distribution, we applied the $t$ test, the Mann-Whitney $U$ test or the Kruskal-Wallis test (followed by Dunn-Bonferroni post hoc test). All reported $p$ values were adjusted for multiple comparisons. We adopted the Chi-square test for categorical variables. Differences were considered statistically significant at $p<0.05$.

For the present study, no authorization to an Ethics Committee was asked, because the original reports, nor this work, provided any personal information of the patients.

\section{Results}

Our literature search identified 101 papers, including 37 case reports, 12 case series, 3 reviews with case reports, 42 reviews, 4 letters, 1 original article, 1 point of view, and 1 brief report. Four and one patients were excluded from the analysis because of a missing laboratory-proven SARS$\mathrm{CoV}-2$ infection or an ambiguous GBS diagnosis [disease course resembling chronic inflammatory demyelinating neuropathy (CIDP)], respectively. A total of 52 studies were included in the final analysis (total patients $=73$ ) [5-56]. All data concerning the analyzed patients are reported in Table 1. For one case [20], most clinical and diagnostic details were not reported; therefore, many of our analyses were limited to 72 patients.

\section{Epidemiological distribution and demographic characteristics of the patients}

To date, GBS cases $(n=73)$ were reported from all continents except Australia. In details, patients were originally from Italy $(n=20)$, Iran $(n=10)$, Spain $(n=9)$, USA $(n=8)$, United Kingdom $(n=5)$, France $(n=4)$, Switzerland $(n=4)$, Germany $(n=3)$, Austria $(n=1)$, Brazil $(n=1)$, Canada $(n=1)$, China $(n=1)$, India $(n=1)$, Morocco $(n=1)$, Saudi Arabia $(n=1)$, Sudan $(n=1)$, The Netherlands $(n=1)$, and Turkey $(n=1)$ (Table 1, Fig. 1). The mean age at onset was $55 \pm 17$ years (min 11-max 94), including four pediatric cases $[21,27,35,41]$. A significative prevalence of men 
compared to women was noticed (50 vs. 23 cases: $68.5 \%$ vs. $31.5 \%$ ) with no significant difference in age at onset between men and women (mean: $55 \pm 18$ vs. $56 \pm 16$ years, $p=0.643$ ). Comorbidities were variably reported with no prevalence of a particular disease.

\section{Clinical picture, diagnosis, and therapy of COVID-19}

All reported GBS cases $(n=72)$ except two were symptomatic for COVID-19 with various severity. Most common manifestations of COVID-19 included fever $(73.6 \%, 53 / 72)$, cough $(72.2 \%, 52 / 72)$, dyspnea and/or pneumonia $(63.8 \%$, $46 / 72)$, hypo-/ageusia $(22.2 \%, 16 / 72)$, hypo-/anosmia $(20.8 \%, 15 / 72)$, and diarrhea $(18.1 \%, 13 / 72)$. One of the two asymptomatic subjects never developed fever, respiratory symptoms, or pneumonia [10], whereas the other patient showed an asymptomatic pneumonia at chest computed tomography (CT) [12]. In all but six patients with available data [22, 24, 36, 44, 45, 52], SARS-CoV-2 RT-PCR with naso- or oropharyngeal swab or fecal exam was positive at first or following tests. Nevertheless, these six patients tested positive at SARS-CoV-2 serology. In four patients, the laboratory exam for the diagnostic confirmation was not specified $[20,40]$. Typical "ground glass" aspects at chestCT or similar findings at CT, Magnetic Resonance Imaging (MRI) or X-ray compatible with COVID-19 interstitial pneumonia were reported in 40 cases. The detailed therapies for COVID-19 are described in Table 1.

\section{Clinical features of GBS spectrum}

In all $(n=72)$ but four patients [10, 37, 40, 56], GBS manifestations developed after those of COVID-19 [median (IQR): 14 (7-20), min 2-max 33 days]. Differently, COVID-19 symptoms began concurrent in one case [37], 1 day [40] and 8 days [55] after GBS onset in two other cases and never developed in another one [10] (Table 1). Common clinical manifestations at onset included sensory symptoms (72.2\%, $52 / 72$ ) alone or in combination with paraparesis or tetraparesis $(65.2 \%, 47 / 72$, respectively). Cranial nerve involvement (e.g., facial, oculomotor nerves) was less frequently described at onset $(16.7 \%, 12 / 72)$. Moreover, all cases but one [26] showed lower limbs or generalized areflexia, whereas in $37.5 \%$ (27/72) of the cases, gait ataxia was reported at onset or during the disease course. Even if ascending weakness evolving into flaccid tetraparesis $(76.4 \%, 55 / 72)$ and spreading/persistence of sensory symptoms $(84.7 \%, 61 / 72)$ represented the most common clinical evolutions, $50.0 \%$ (36/72) and $23.6 \%$ (17/72) patients showed cranial nerve deficits and dysphagia, respectively, during disease course (Table 1). Moreover, $36.1 \%$ (26/72) of the patients developed respiratory symptoms, and some of them evolved to respiratory failure (Table 1). Autonomic disturbances were rarely reported
(16.7\%, 12/72). In cases with MFS/MFS-GBS overlap, areflexia, oculomotor disturbances, and ataxia were present in $100 \%(9 / 9), 66.7 \%(6 / 9)$ and $66.7 \%(6 / 9)$, respectively [8, 19, $23,30,32,33,43,44]$. The median of time to nadir was calculated in 40 patients with available data and resulted 4 days (IQR 3-9) (Table 1).

\section{Results of electrophysiological, CSF, biochemical, and neuroimaging investigations}

Detailed electroneurography results were reported in $84.9 \%$ (62/73) of the cases. Specifically, $77.4 \%$ (48/62) cases showed a pattern compatible with a demyelinating polyradiculoneuropathy. In contrast, axonal damage was prominent in $14.5 \%(9 / 62)$. In a minority of the patients $(8.1 \%)$, a mixed pattern was reported (5/62). Regarding CSF analysis (full results were available in 59 out of 73 cases), the classical albuminocytological dissociation (cell count $<5 / \mu$ with elevated CSF proteins) was detected in $71.2 \%$ of the cases (42/59) with a median CSF protein of $100.0 \mathrm{mg} / \mathrm{dl}$ (min: 49, $\max : 317 \mathrm{mg} / \mathrm{dl}$ ). Mild pleocytosis (i.e., cell count $\geq 5 / \mu \mathrm{l}$ ), with a maximum cell count of $13 / \mu$, was evident in 5/59 cases (8.5\%). Furthermore, CSF SARS-CoV-2 RNA was undetectable in all tested patients $(n=31)$ (Table 1).

Detailed blood haematological and biochemical examinations showed variably leucocytosis $(n=4)$, leucopenia $(n=17)$, thrombocytosis $(n=3)$, thrombocytopenia $(n=5)$, and increased levels of C-reactive protein (CRP) $(n=22)$, erythrocyte sedimentation rate $(n=4)$, D-Dimer $(n=5)$, fibrinogen $(n=3)$, ferritin $(n=3), \operatorname{LDH}(n=7), \operatorname{IL}-6(n=4)$, IL-1 $(n=3)$, IL-8 $(n=3)$, and TNF- $\alpha(n=3)$ (Table 1$)$.

Furthermore, anti-GD1b and anti-GM1 antibodies were positive in one patient with MFS [23] and in one with classic sensorimotor GBS [13], respectively, whereas 33 cases tested negative (one in equivocal range) for anti-ganglioside antibodies.

Cranial and spinal MRI scans were performed in a minority of the patients $(23 / 73,31.5 \%)$. Five patients (three cases with AIDP [9, 12, 25], one case with MFS [30], and one case with bilateral facial palsy with paresthesia [52]) showed cranial nerve contrast enhancement in the context of correspondent cranial nerve palsies. Moreover, brainstem leptomeningeal enhancement was described in two cases with AIDP, both with clinical cranial nerve involvement $[18,46]$. On the other hand, spinal nerve roots and leptomeningeal enhancement were reported in eight $[9,27,31,36,37,42$, 52] and two cases [17, 46], respectively (Table 1 ).

\section{Distribution of clinical and electrophysiological variants and diagnosis of GBS}

From the clinical point of view, most examined patients presented with a classic sensorimotor variant $(70.0 \%$, 
51/73), whereas Miller Fisher syndrome, GBS/MFS overlap variants (including polyneuritis cranialis), bilateral facial palsy with paresthesia, pure motor, and paraparetic were described in seven, two, five, four, and one patients, respectively. In three cases, no clinical variant could be established using the reported details (Table 1). In the examined population, $81.8 \%$ subjects fulfilled electrophysiological criteria for AIDP (45/55), $12.7 \%$ (7/55) for AMSAN, and 5.4\% (3/55) for AMAN subtypes. Finally, a specific electrophysiological subtype was not attributable in 18 patients due to the lack of detailed information. The diagnosis of GBS was established based on clinical, CSF, and electrophysiological findings in 44/73 (60.3\%) patients, clinical, and electrophysiological data in $18 / 73$ (24.7\%) cases, clinical, and CSF data in $8 / 73$ (11.0\%), and only clinical findings in 3/73 (4.1\%) patients. Indeed, the highest level of diagnostic certainty (level one) was confirmed in $44 / 73$ cases $(60.3 \%)$. Level two and three were obtained in $24 / 73$ cases $(32.9 \%)$ and $5 / 73(6.8 \%)$, respectively (Table 1).

\section{Management of GBS and patient outcomes}

All cases with available therapy data $(n=70)$ except ten [13, $15,23,25,26,33,35-37,41]$ were treated with intravenous immunoglobulin (IVIG) (Table 1). Conversely, plasma exchange and steroid therapy were performed in ten (four of them received also IVIG) and two cases, respectively. In two patients, no therapy was given. Mechanical or non-invasive ventilation was implemented in $21.4 \%(15 / 70)$ and $7.1 \%$ (5/70) patients due to worsening of GBS or COVID-19, respectively. At further observation $(n=68), 72.1 \%(49 / 68)$ patients demonstrated clinical improvement with partial or complete remission, $10.3 \%$ (7/68) cases showed no improvement, $11.8 \%(8 / 68)$ still required critical care treatment, and $5.8 \%(4 / 68)$ died (Table 1).

Interestingly, patients with no improvement or poor outcome $(n=19)$ showed a slightly higher (but not significant) frequency of clinical history and/or a radiological picture of COVID-19 pneumonia (14/19, 73.7\%) compared to those with a favorable prognosis $(29 / 48,60.4 \%$, $p=0.541)$. Moreover, the former group of patients was significantly older (mean $62.7 \pm 17.8$ years, $p=0.011$ ), but with comparable distribution of $\operatorname{sex}(p=0.622)$ and electrophysiological subtypes $(p=0.144)$ and similar latency between COVID-19 and GBS $(p=0.588)$ and nadir $(p=0.825)$, compared to the latter (mean age $51.8 \pm 16.6$ years). The same findings were confirmed even after excluding cases with no improvement from the analysis (to prevent a possible bias related to the short follow-up time).

\section{Discussion}

COVID-19 pandemic prompts all efforts for the early recognition and treatment of its manifestations. In analogy to other viruses, belonging or not to the coronavirus family [63, 67], neurologic complications in COVID-19 are emerging as one of the most significant clinical chapters of this pandemic. In this regard, peripheral and central nervous system damage in COVID-19 has been postulated to be the consequence of two different mechanisms: 1) hematogenous (infection of endothelial cells or leucocytes) or trans-neuronal (via olfactory tract or other cranial nerves) dissemination to central nervous system in relation with viral neurotropism, and 2) abnormal immune-mediated response causing secondary neurological involvement [62, 68, 69]. The first mechanism is supposed to be responsible for the most common neurological symptoms developed by patients with COVID-19 (e.g., hypogeusia, hyposmia, headache, vertigo, and dizziness). In contrast, the second can lead to severe complications during or after the course of the illness, either dysimmune (e.g., myelitis, encephalitis, GBS) or induced by cytokine overproduction (hypercoagulable state and cerebrovascular events) [68, 69].

In the present systematic review, we reviewed clinical features, results of diagnostic investigations, and outcome in 73 cases of COVID-19-associated GBS spectrum [5-56].

In the present study, mean age at onset in patients with GBS largely overlapped that of classic COVID-19 subjects $[70,71]$. However, pediatric cases with GBS have been increasingly reported in the literature [21, 27, 35, 41], suggesting that, with the spreading of the pandemic, a broader age range might be affected. Moreover, we found a higher prevalence of GBS in males compared to females, as previously reported for Zika virus-GBS [72]. This finding may also reflect the gender epidemiology of SARS-CoV-2. In this regard, males typically show a worse COVID-19 outcome compared to the females [70, 71], possibly due to a generally shorter life expectancy or to higher circulating AngiotensinConverting-Enzyme 2 (ACE2) levels, the cellular receptor for SARS-CoV-2, in the former compared to the latter [71]. Moreover, given that GBS is a rare disease [57] the epidemiological distribution of the reported cases seems to reflect current worldwide outbreaks, with Europe being the "hottest" spot in March-May 2020 and USA together with Asia in the following period [73, 74]. On another issue, despite a few GBS cases seemed to have a para-infectious profile [10, 37, 38, 40, 55, 56] as described for Zika virus [75], all other reported patients developed neurological symptoms with a typical latency after COVID-19 (median time 14 days). This feature, together with the frequently reported negative nasopharyngeal swab at GBS onset [22, 24, 36, 44, 45, 52] and clinical improvement after IVIG therapy, seems to support 


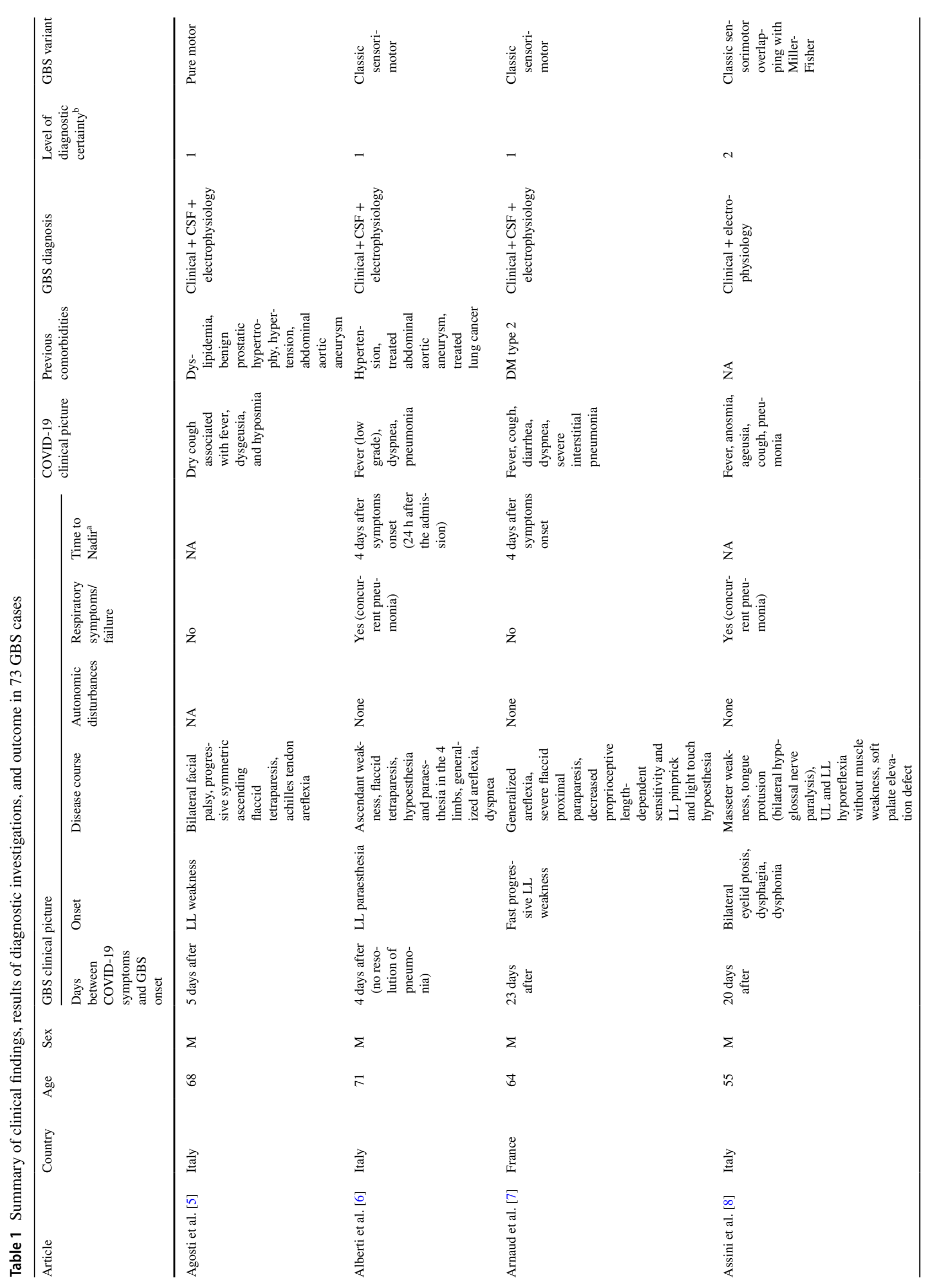




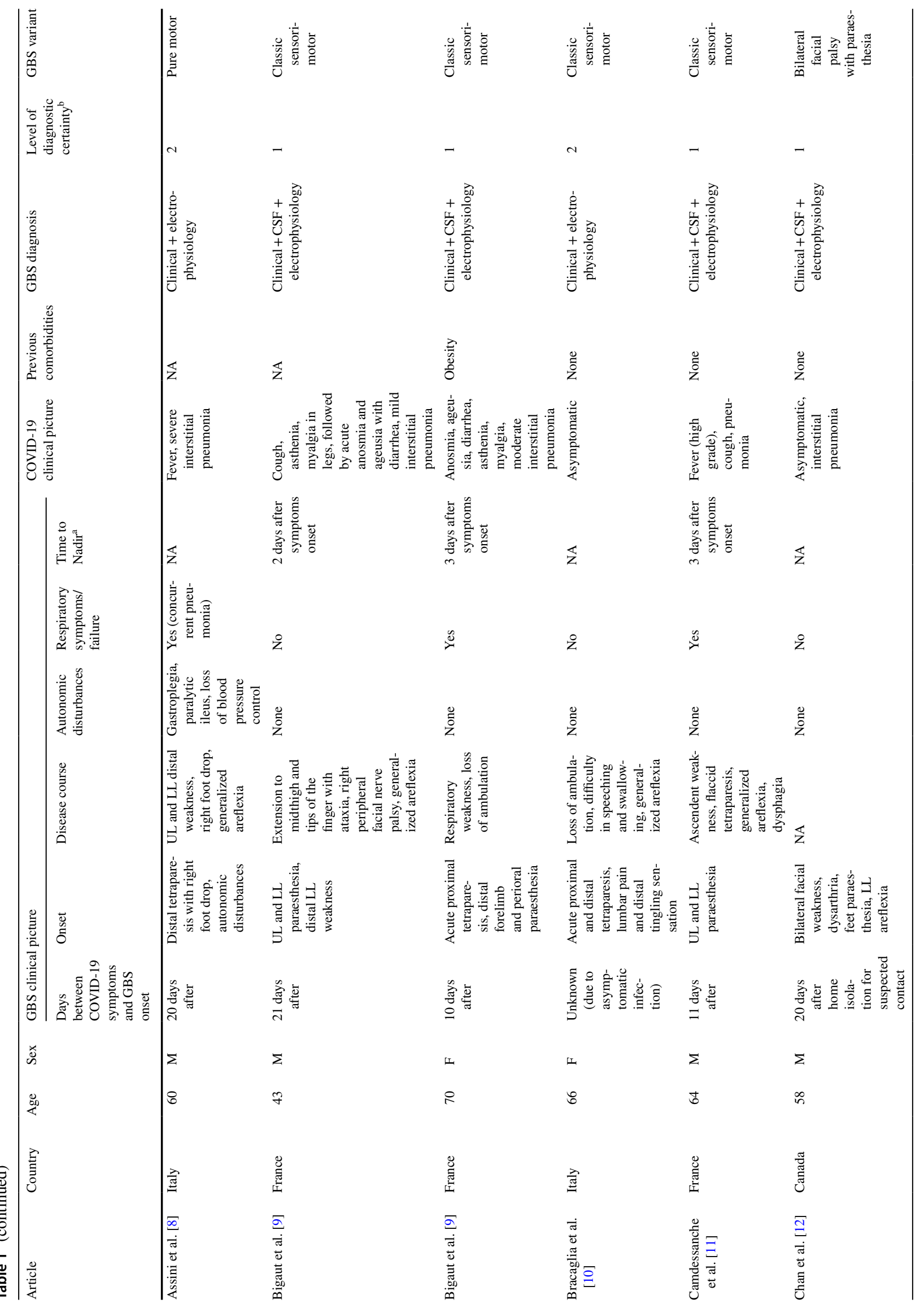




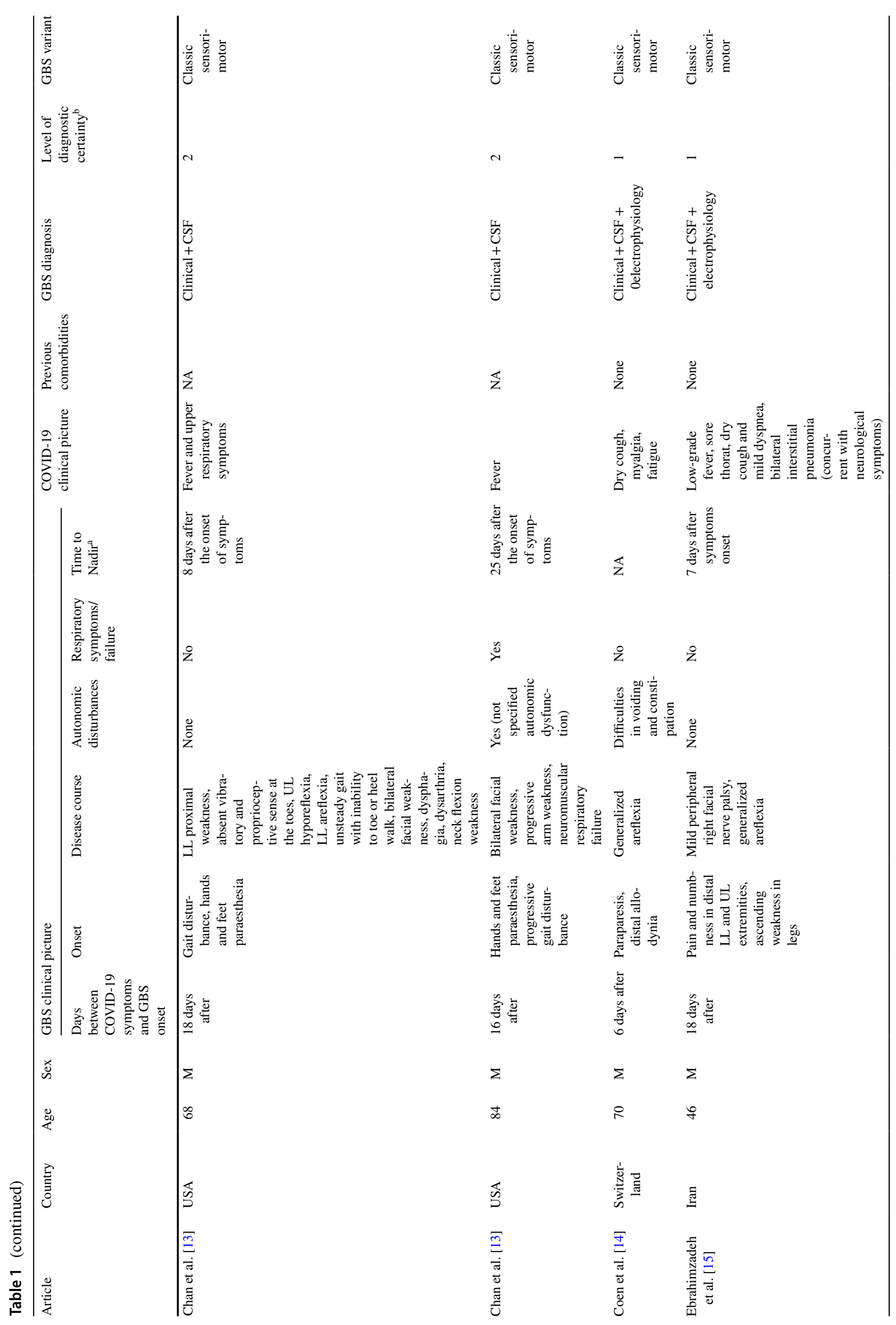




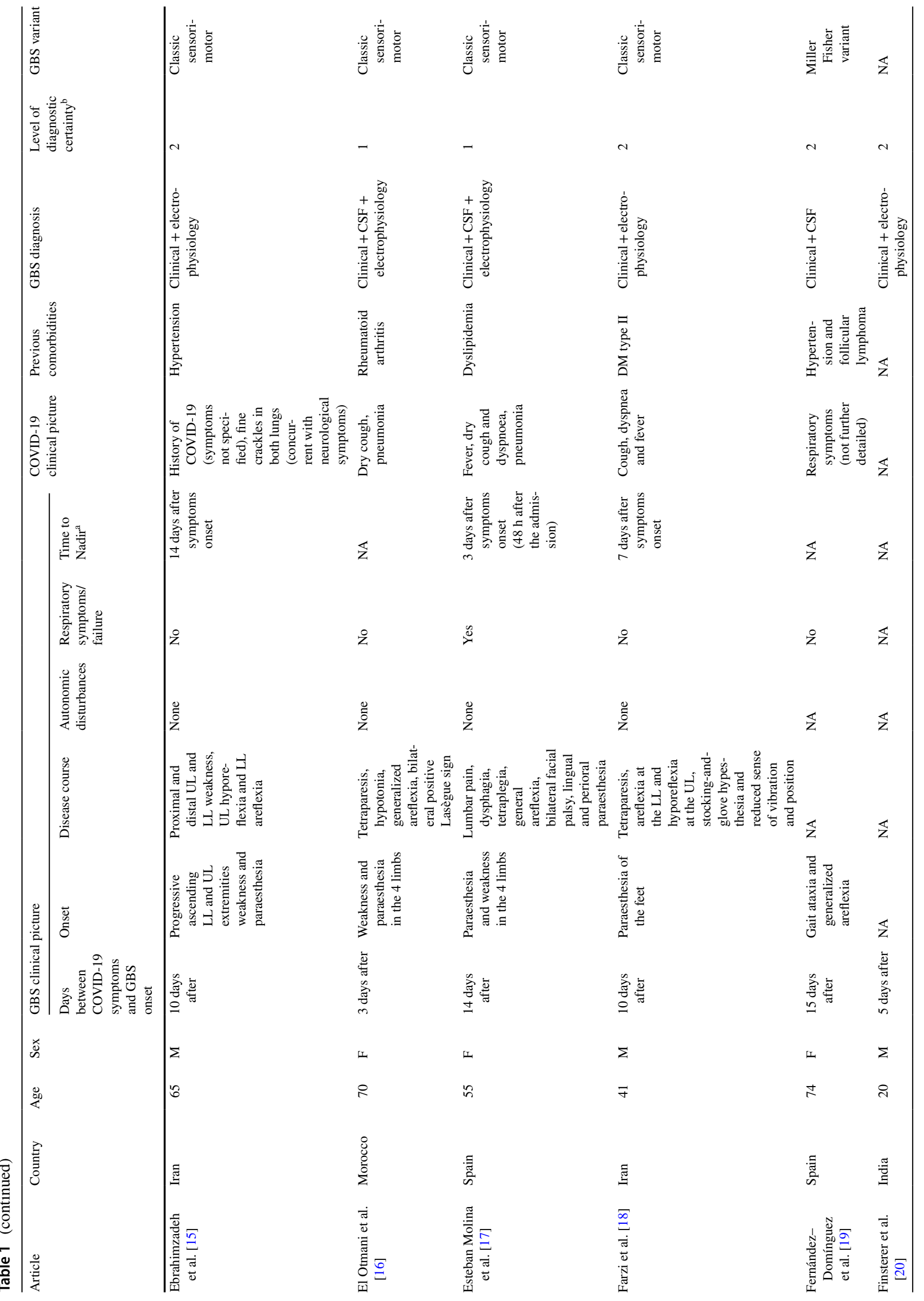




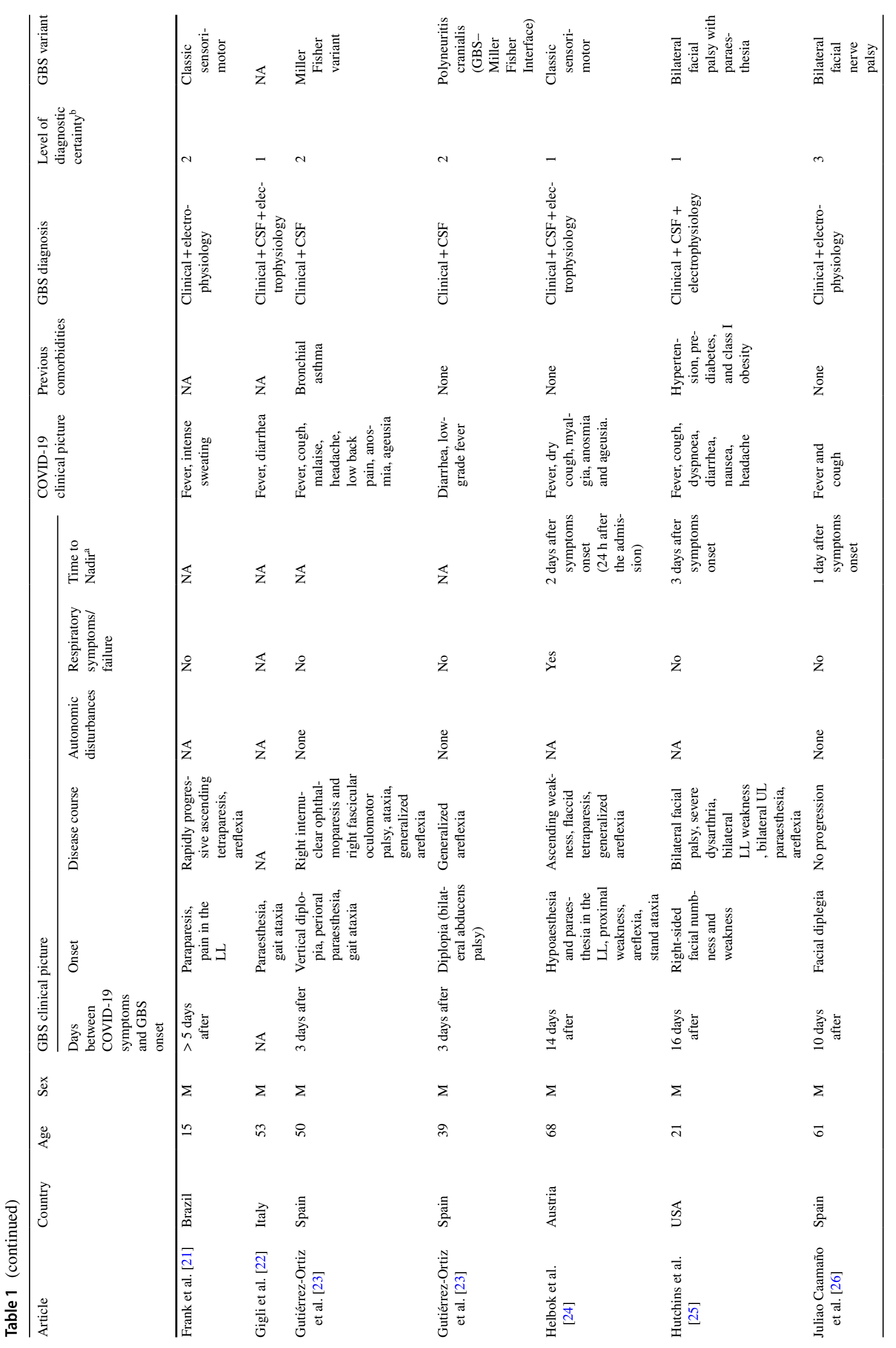




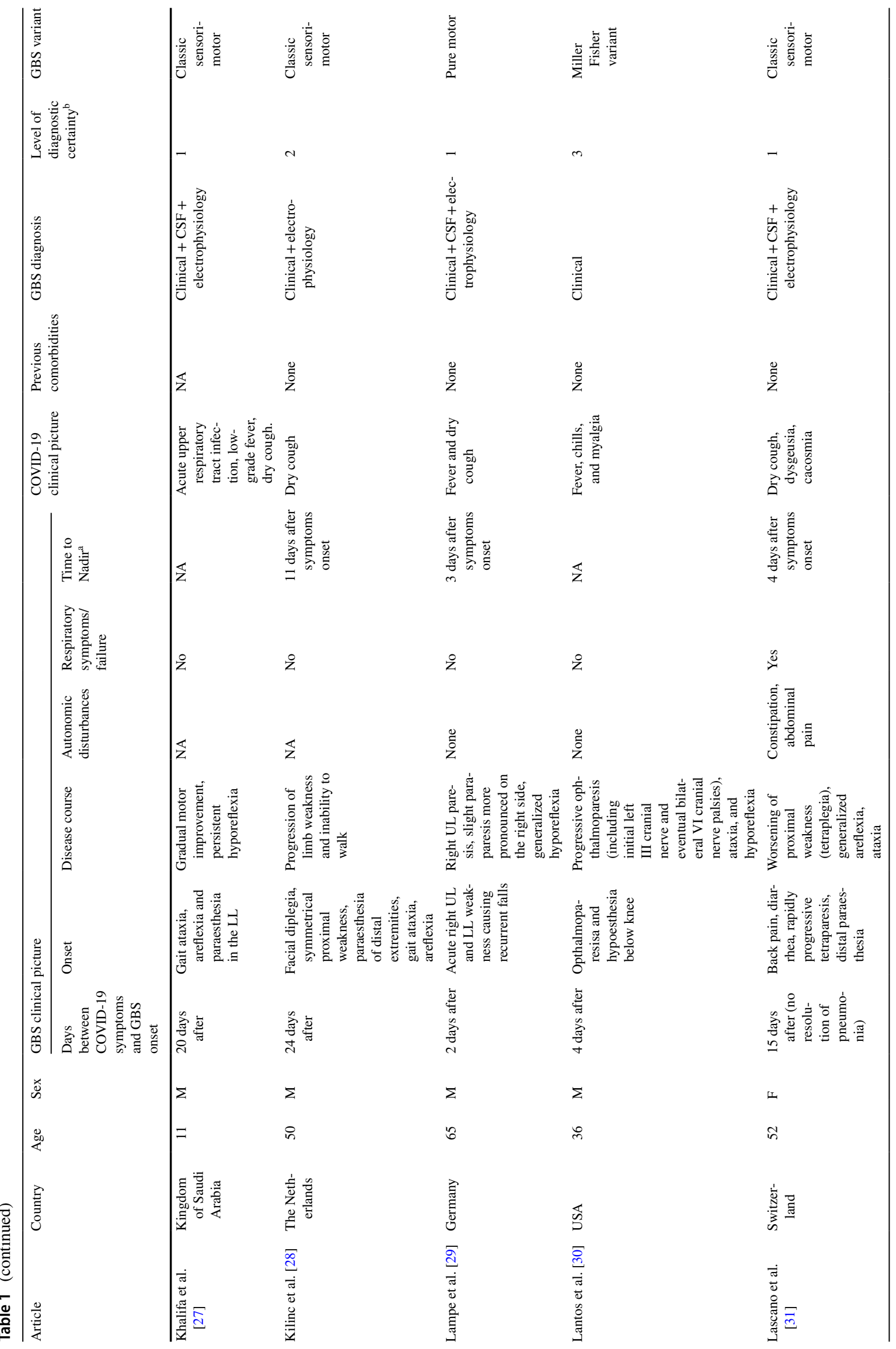




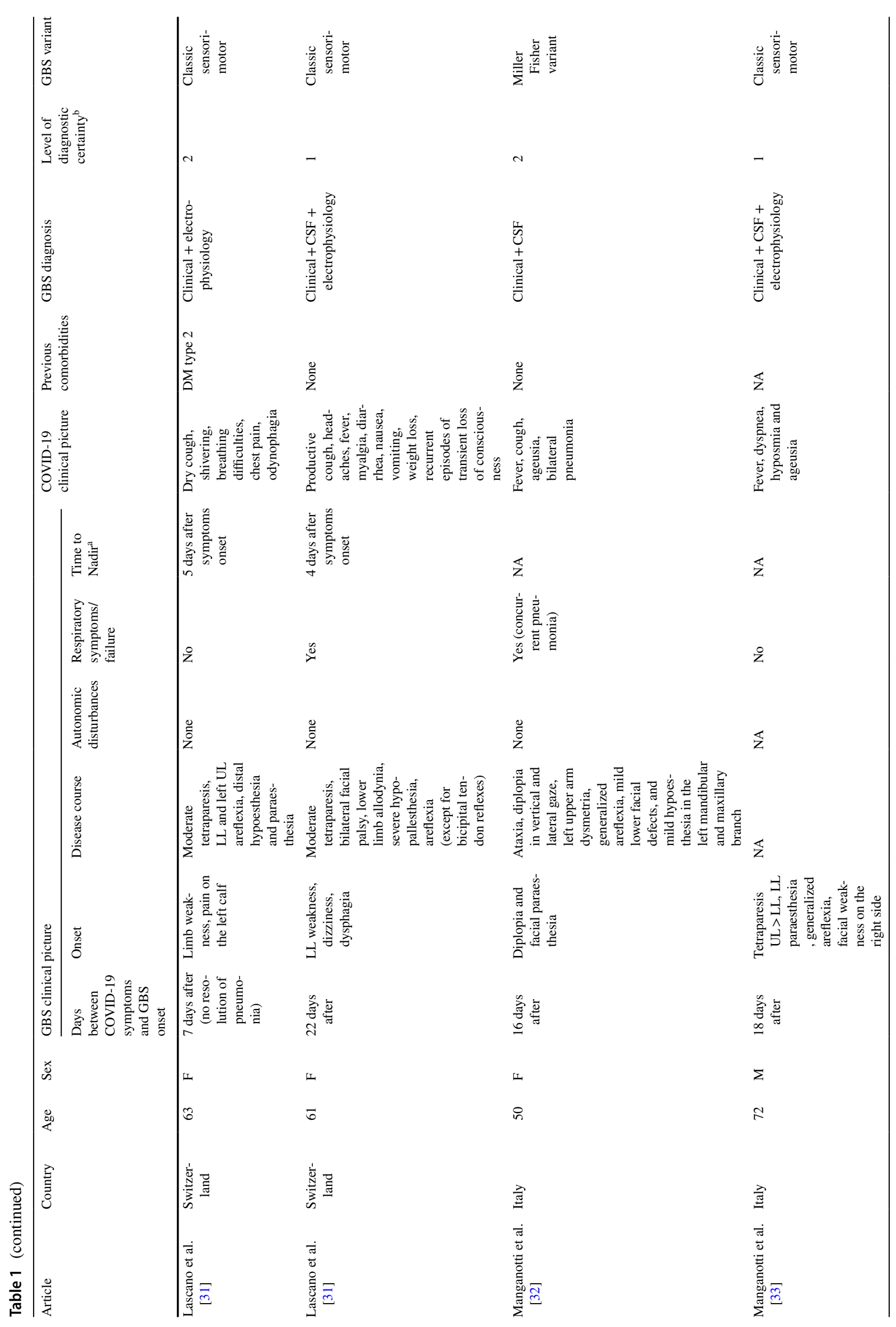




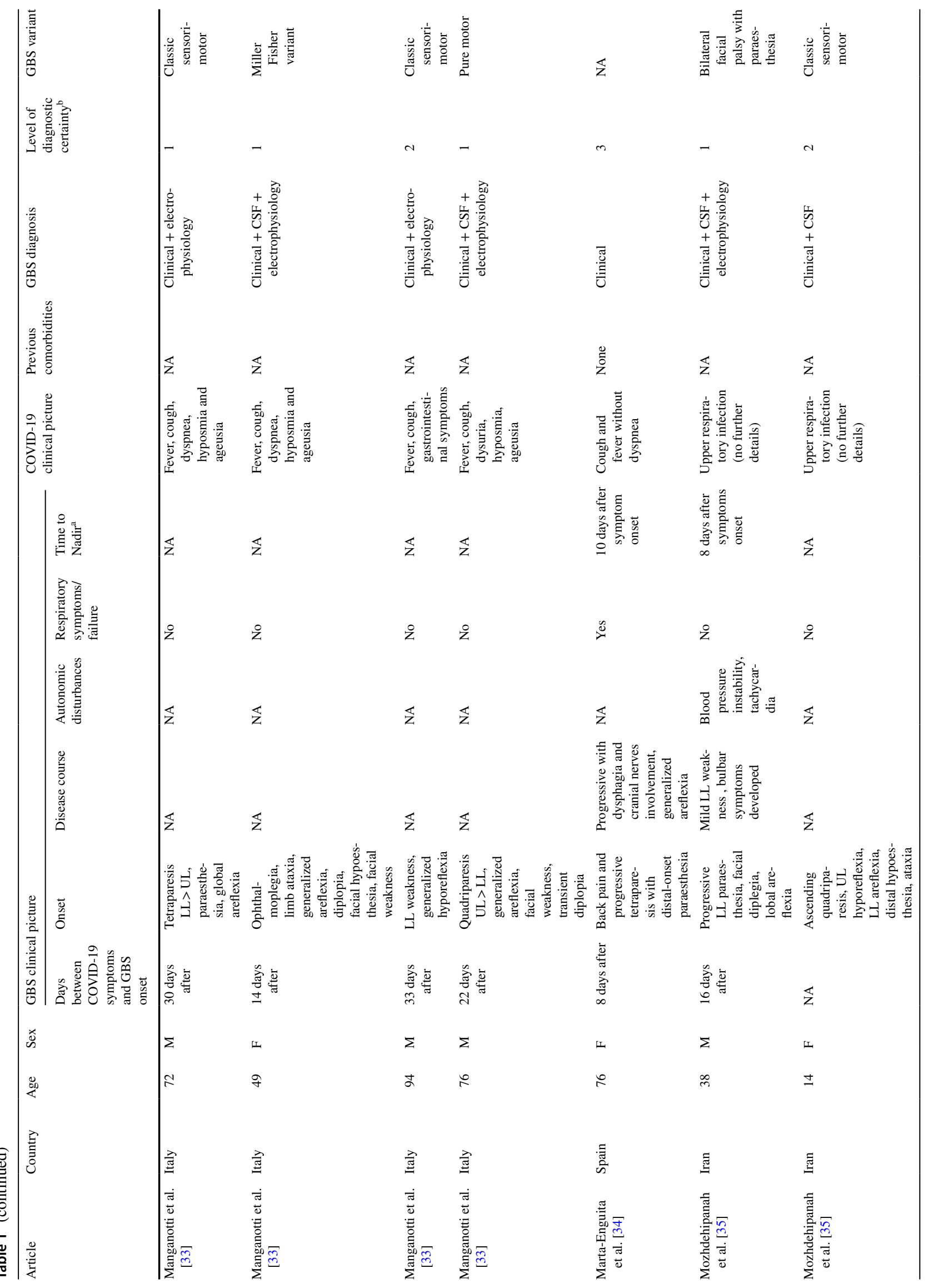




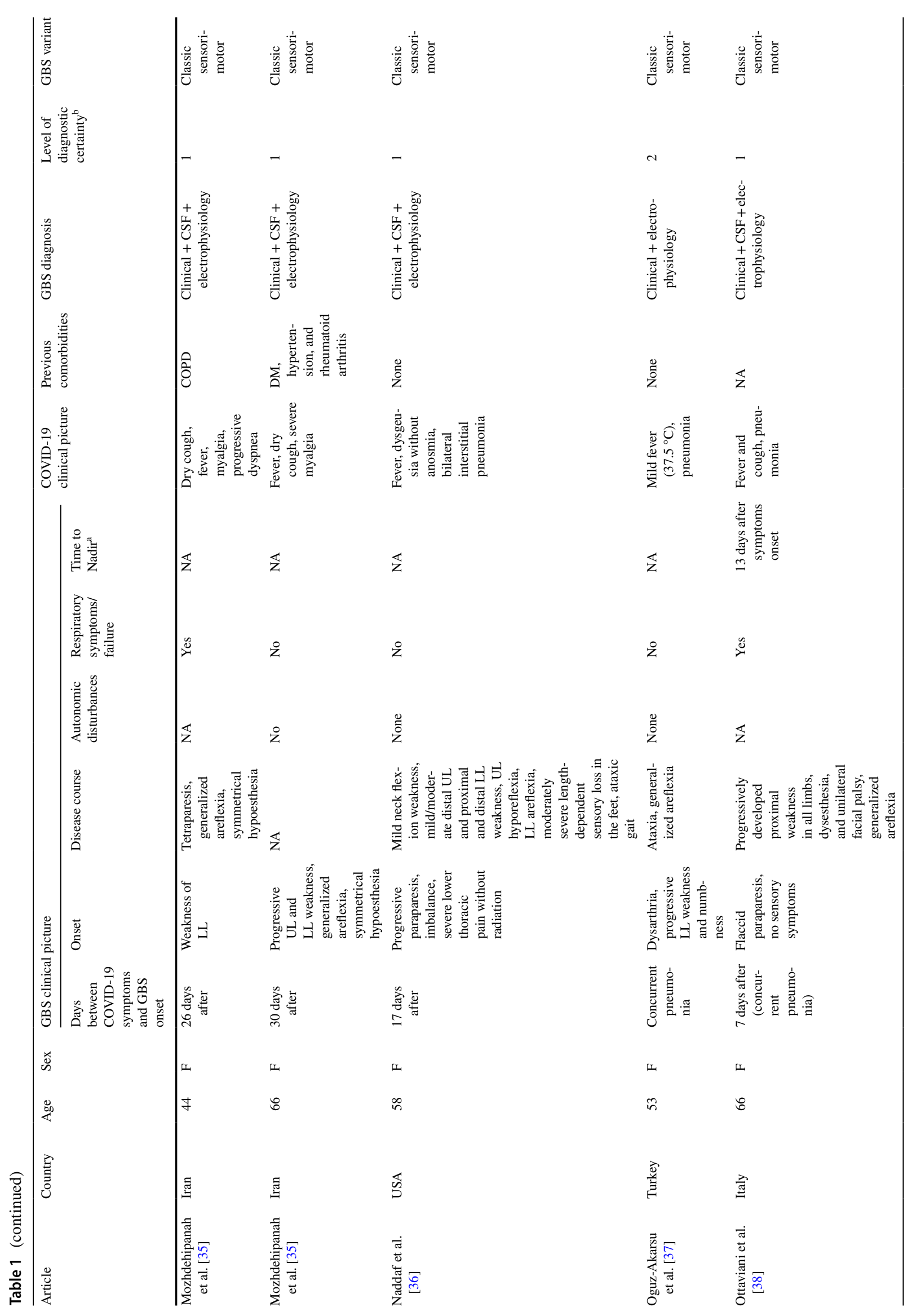


1146

Journal of Neurology (2021) 268:1133-1170

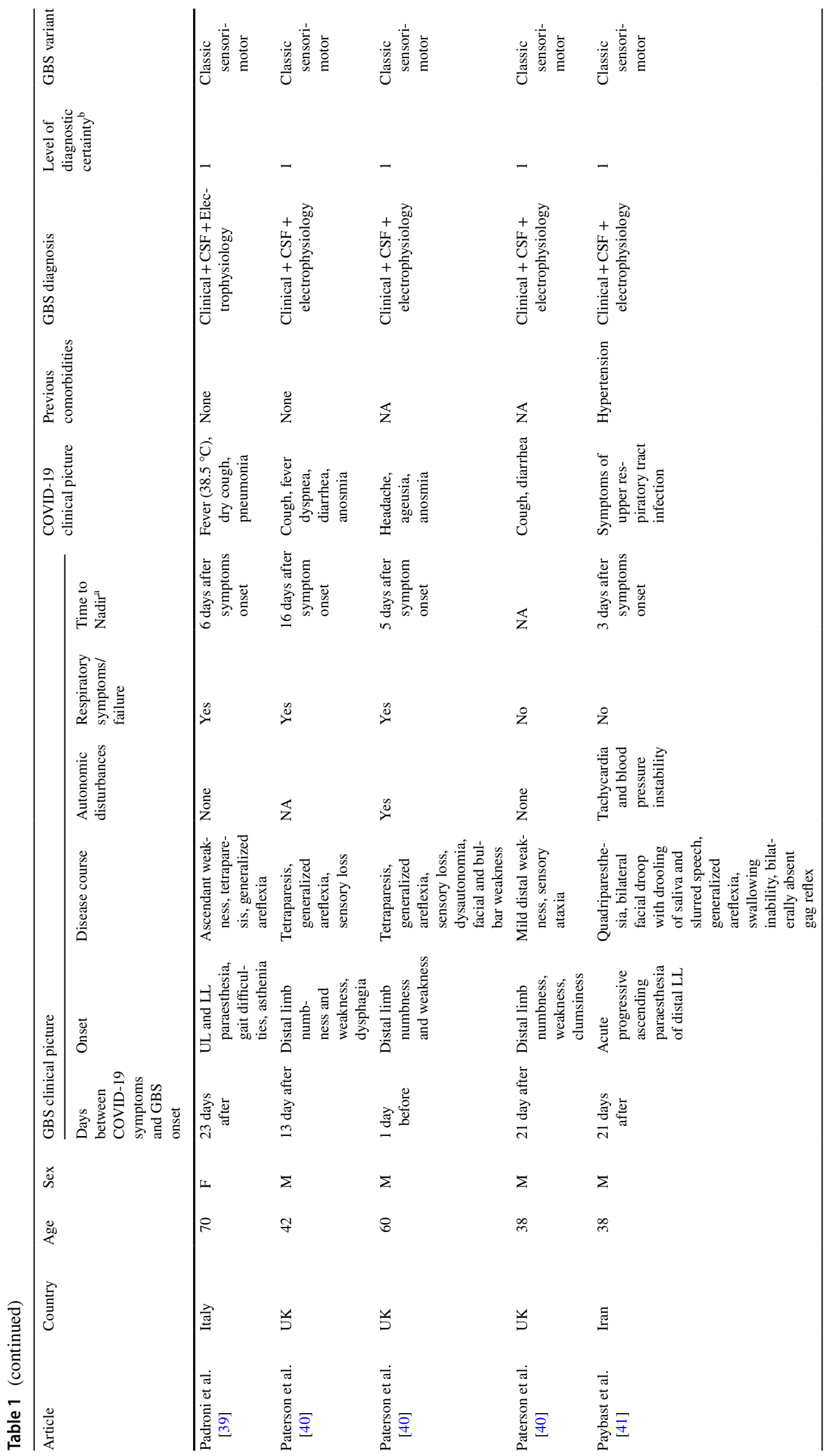

Springer 


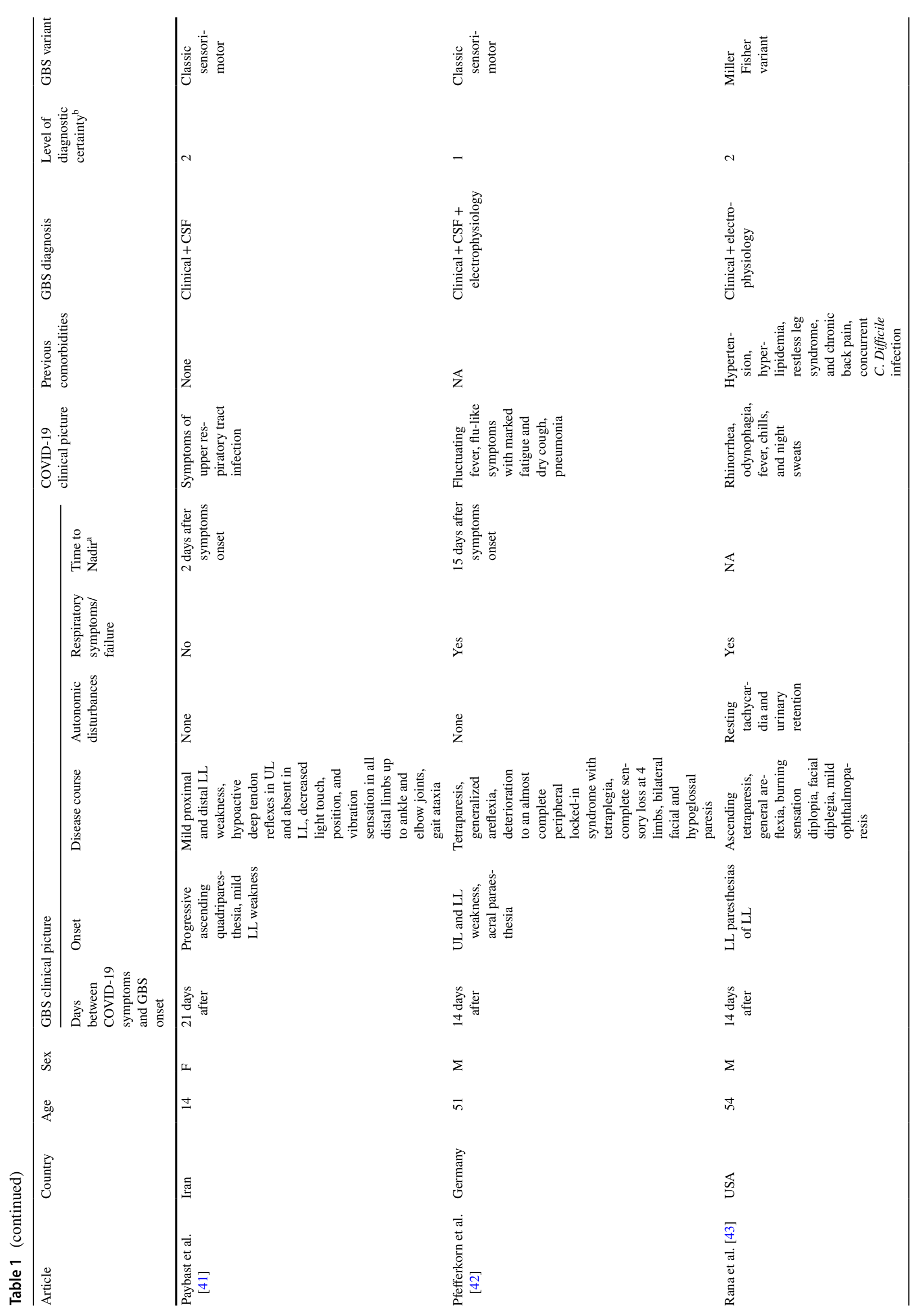




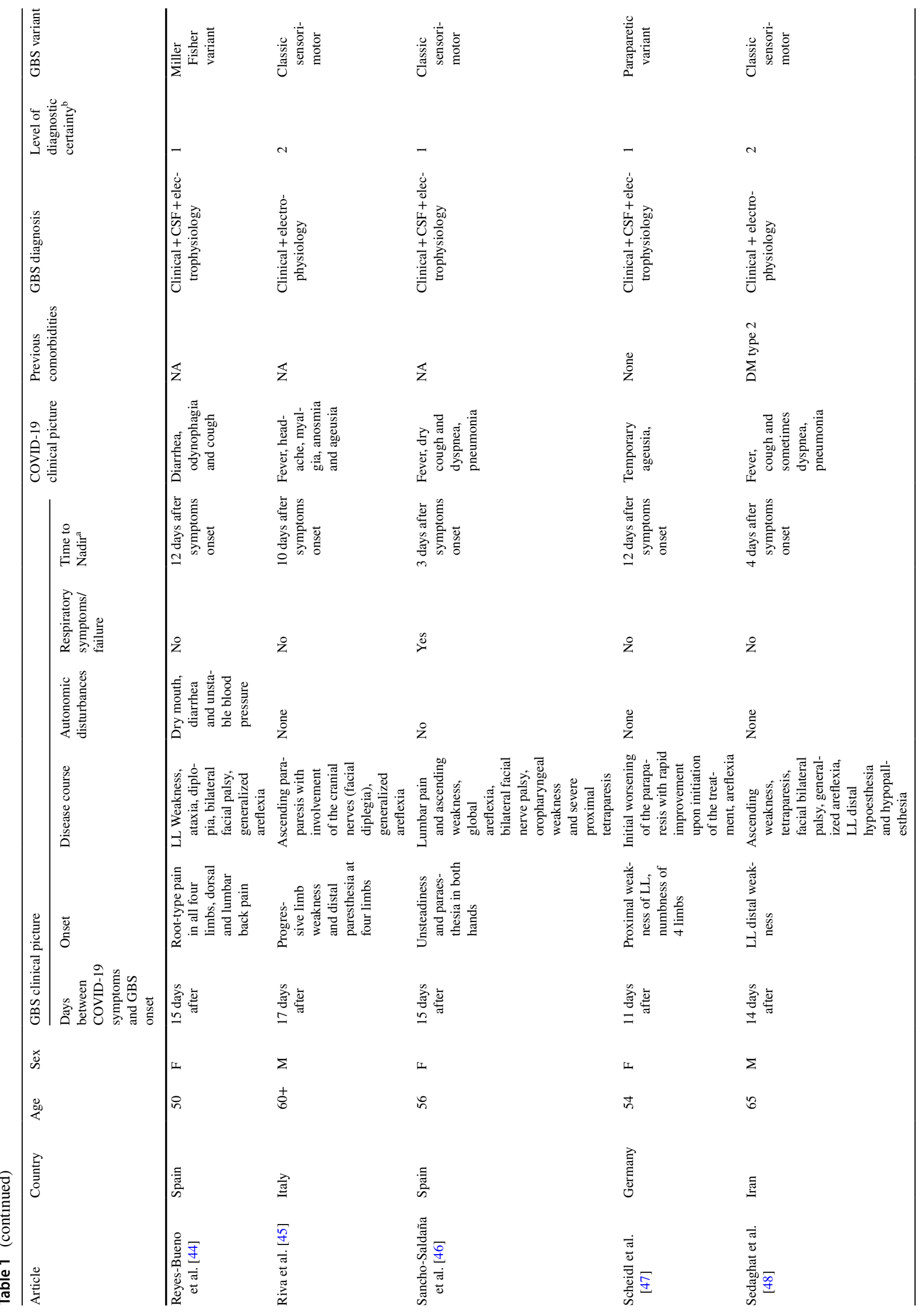




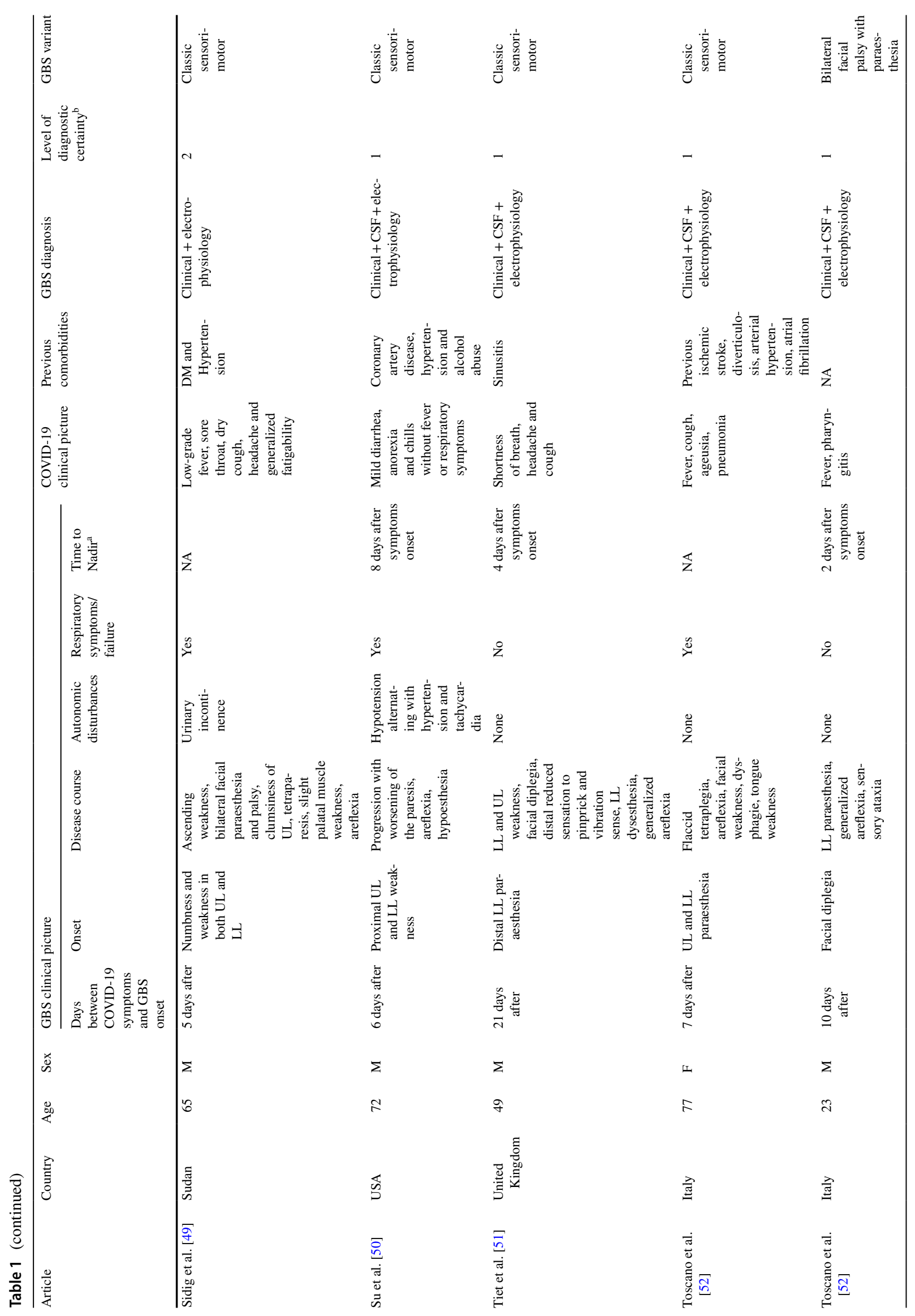




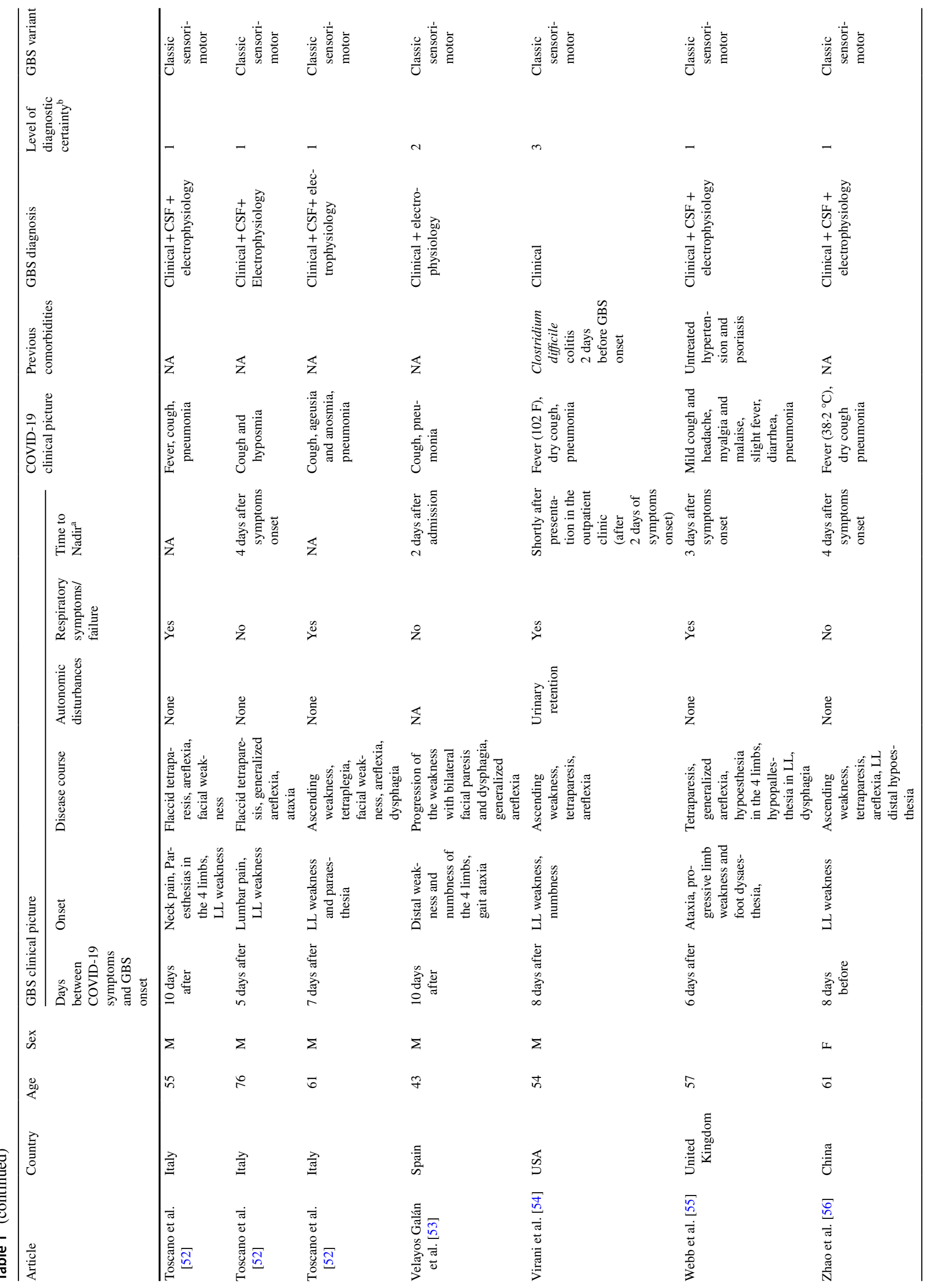




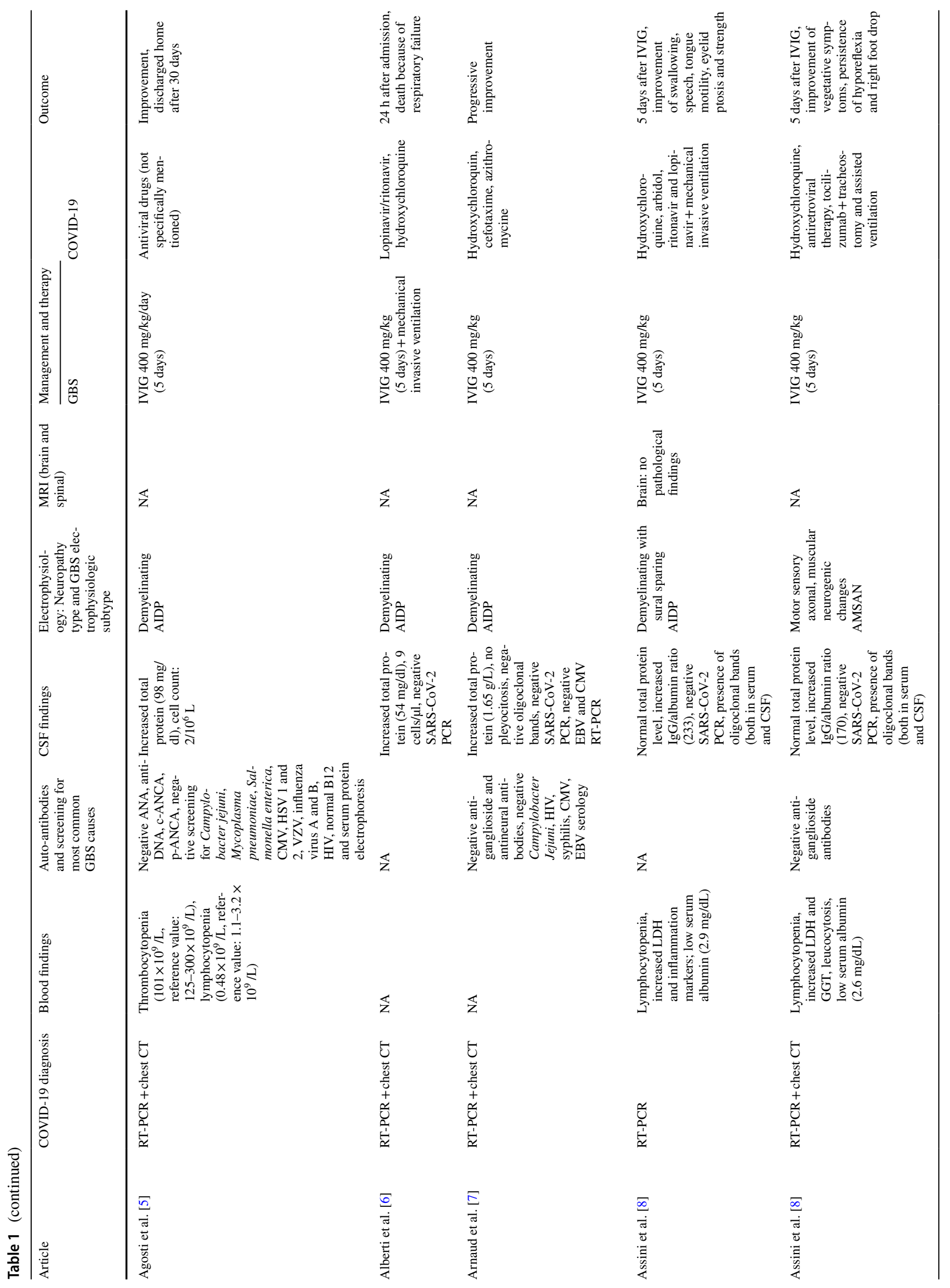




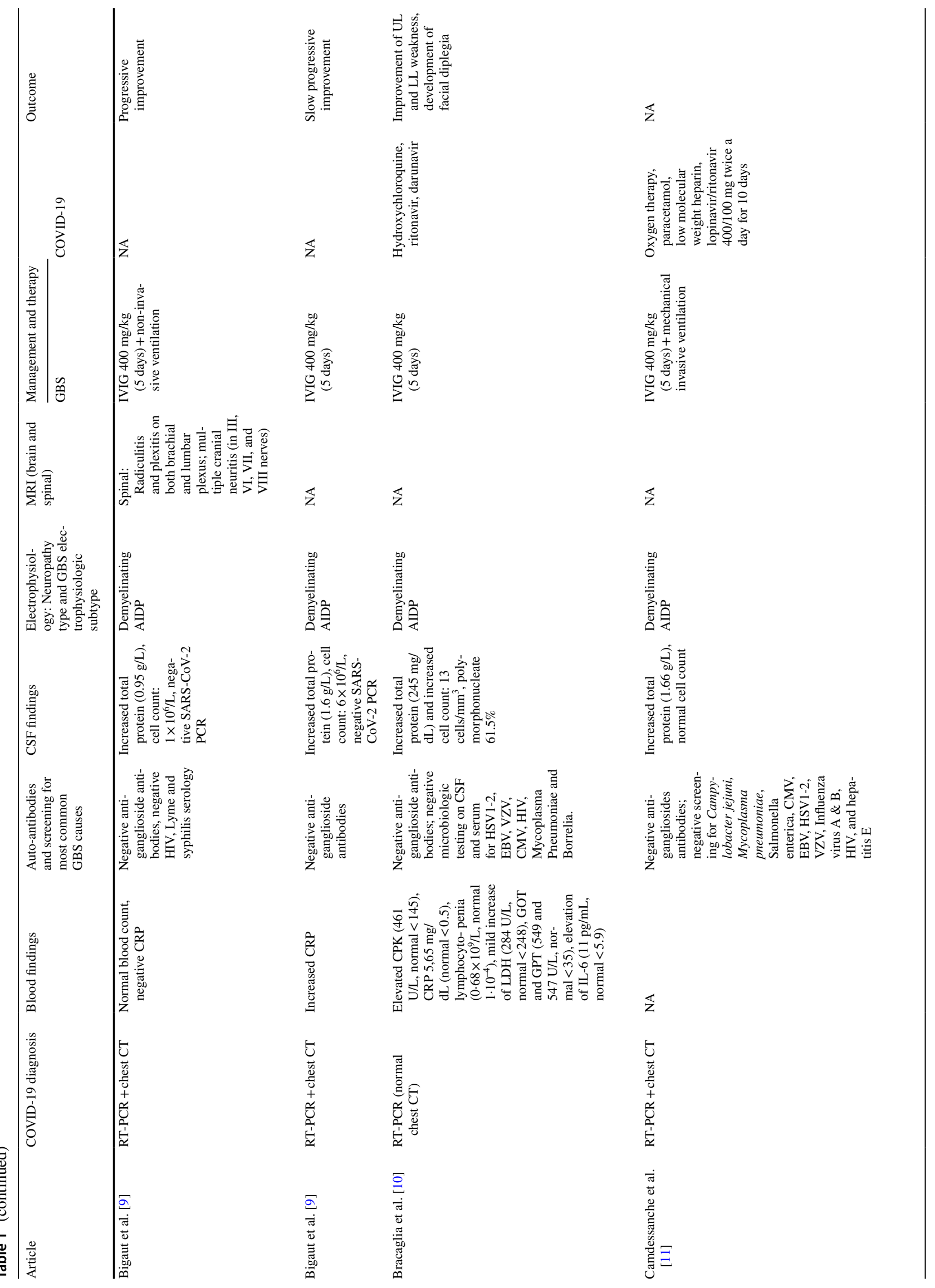




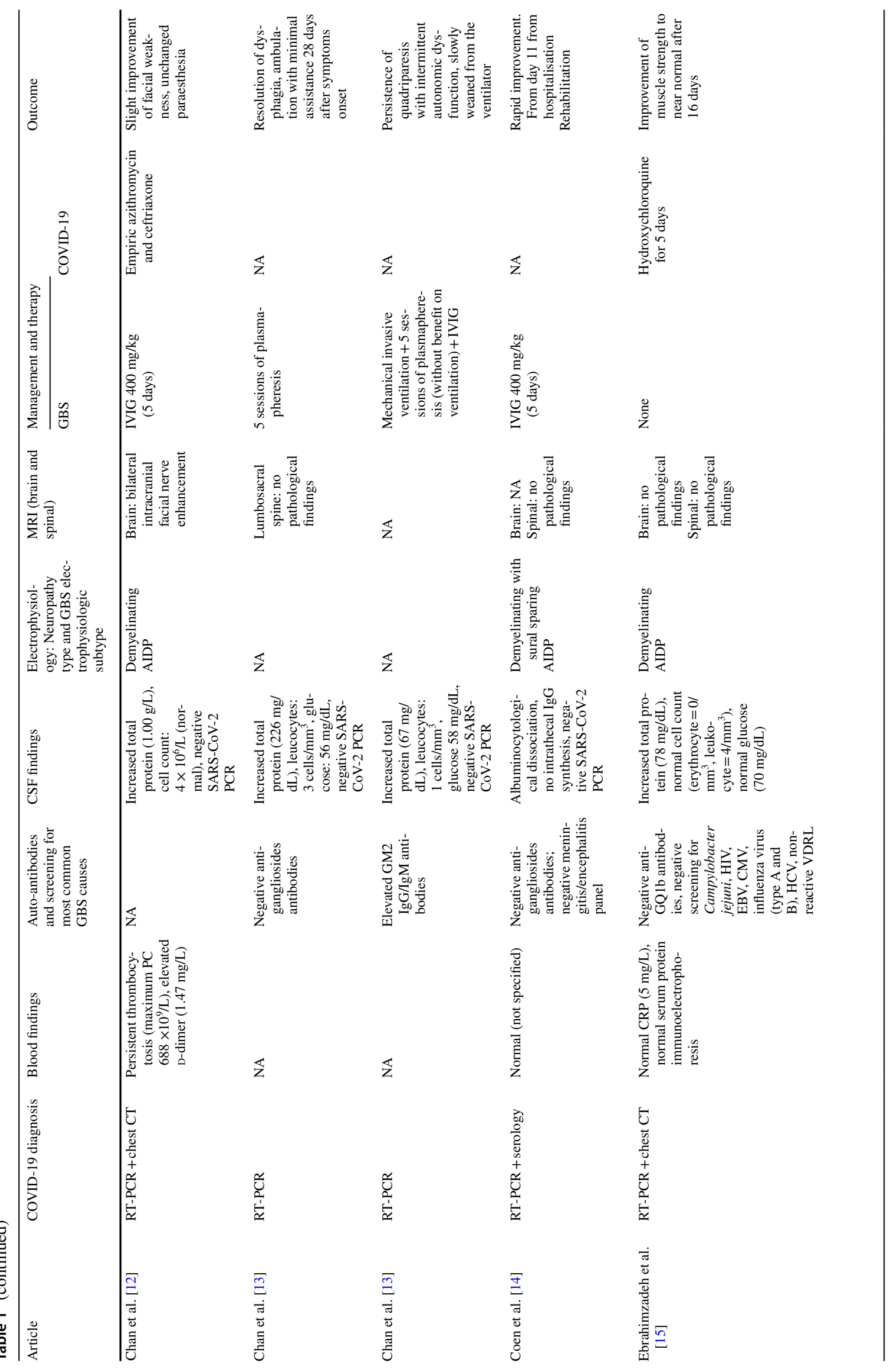




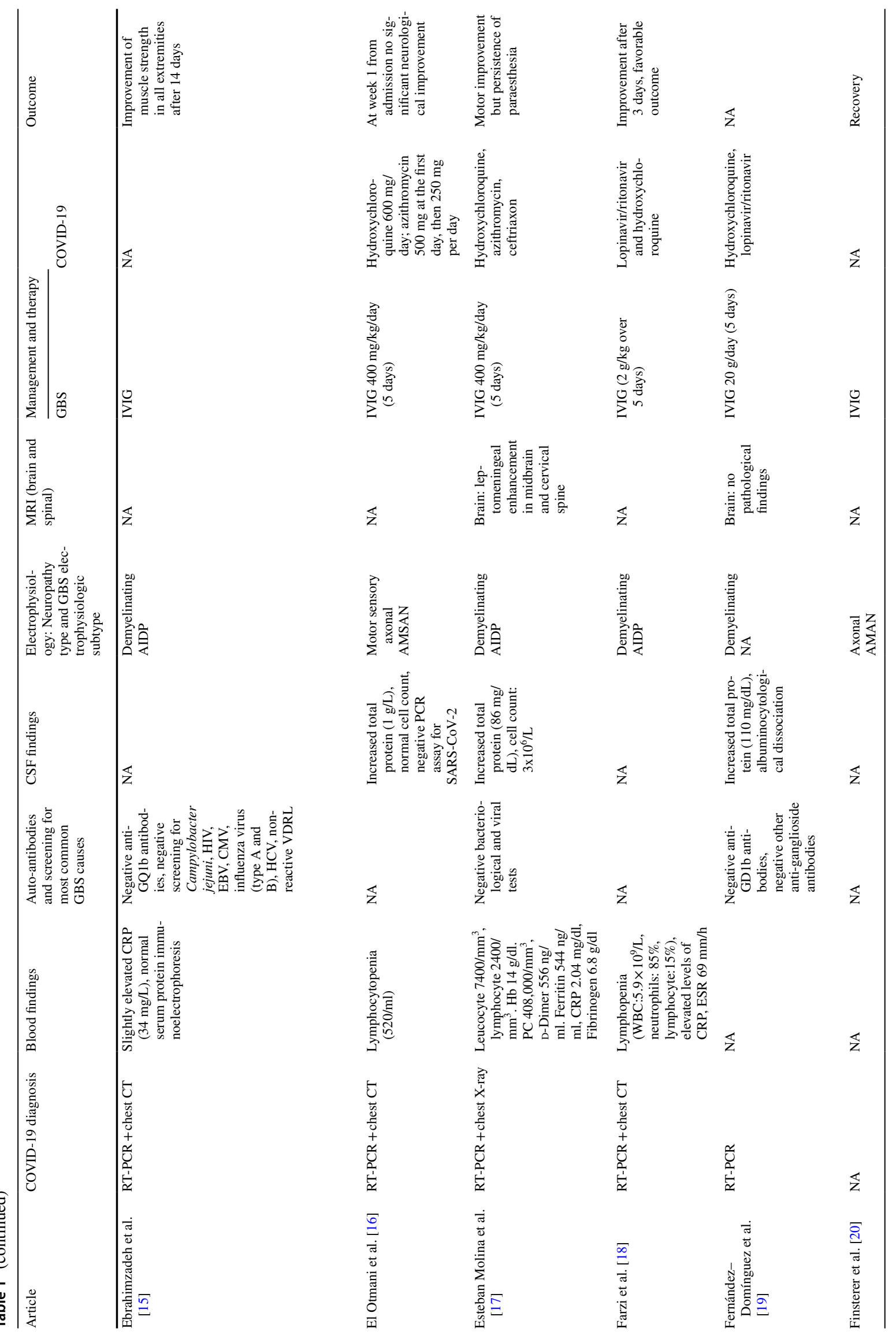




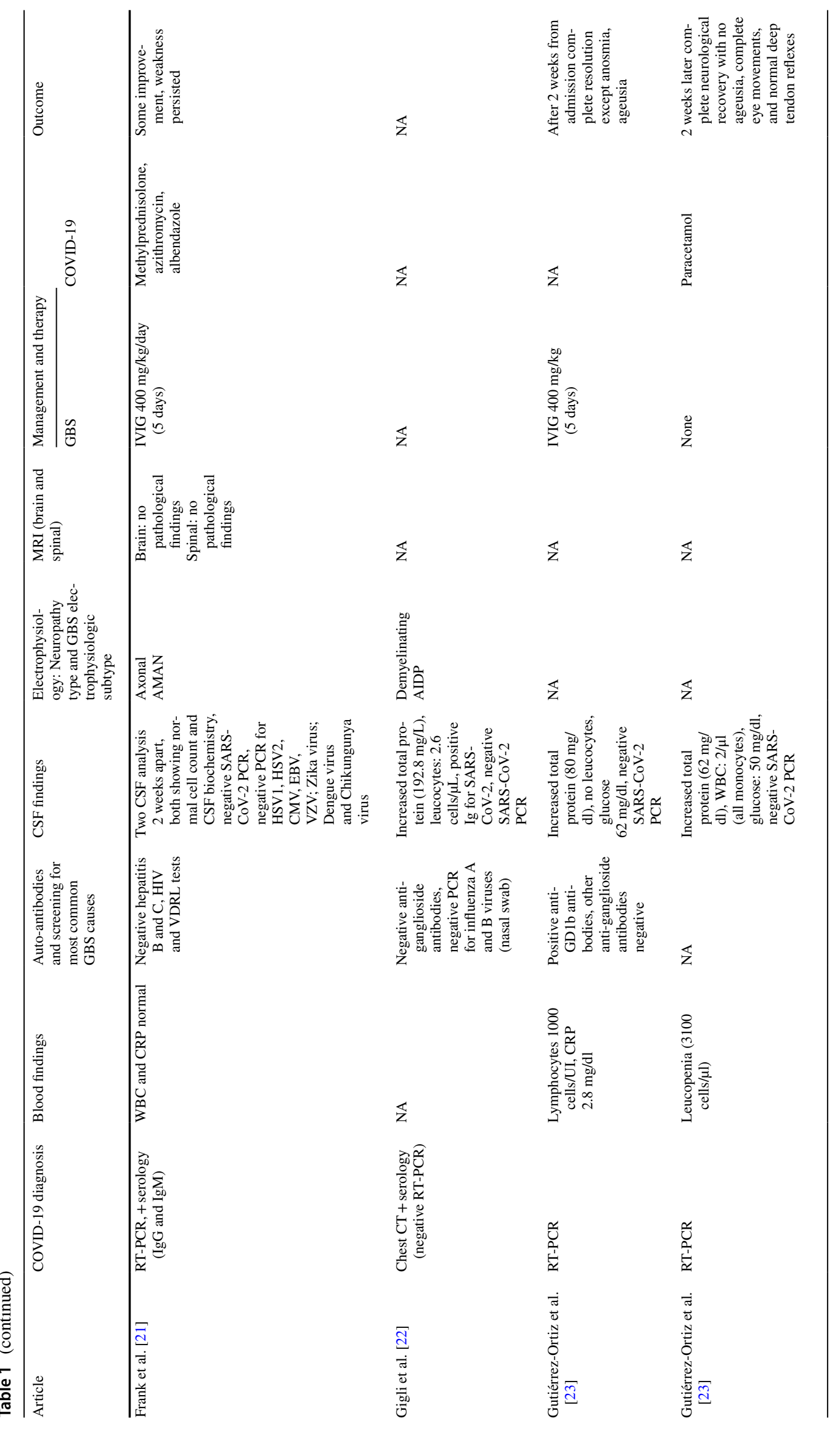




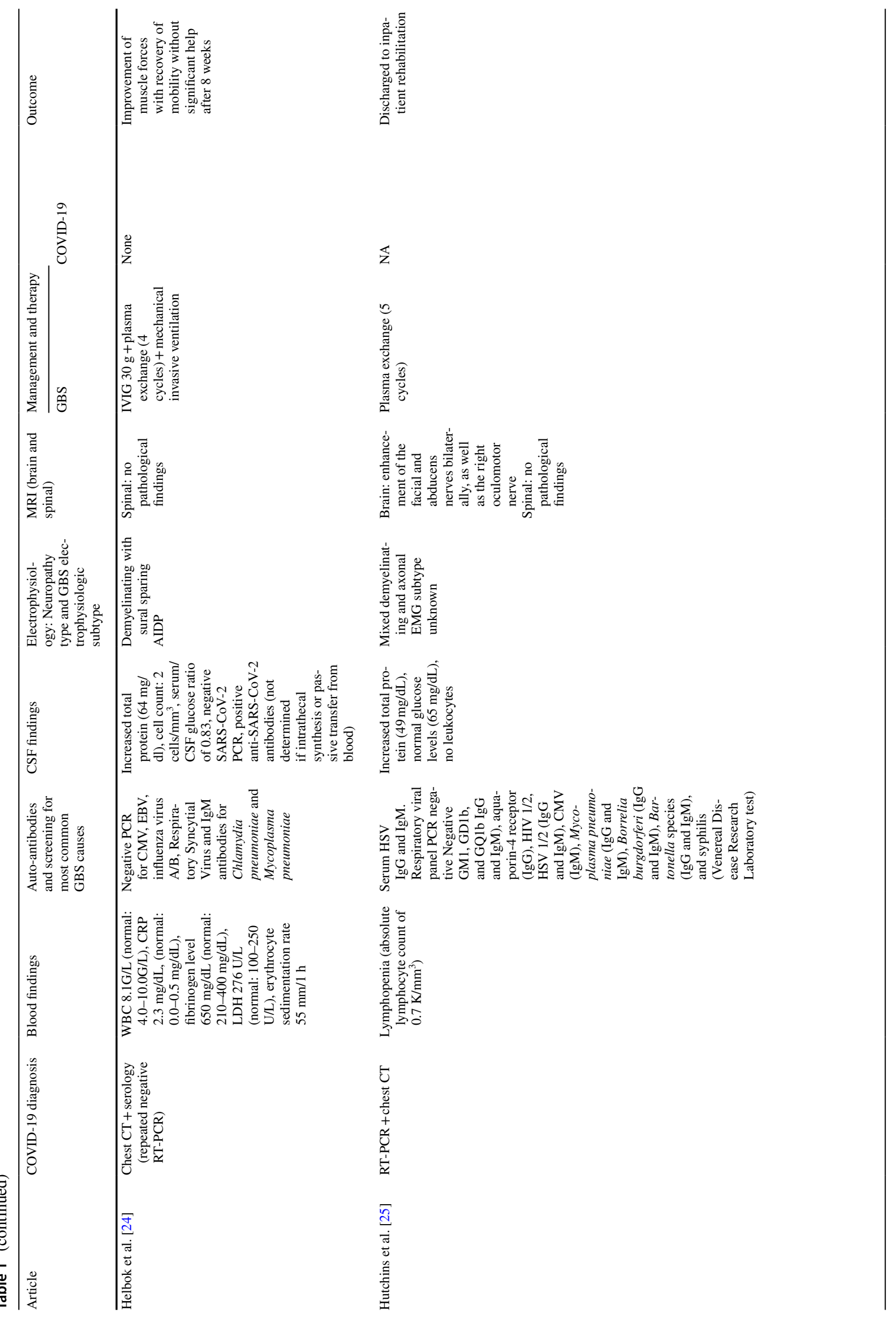




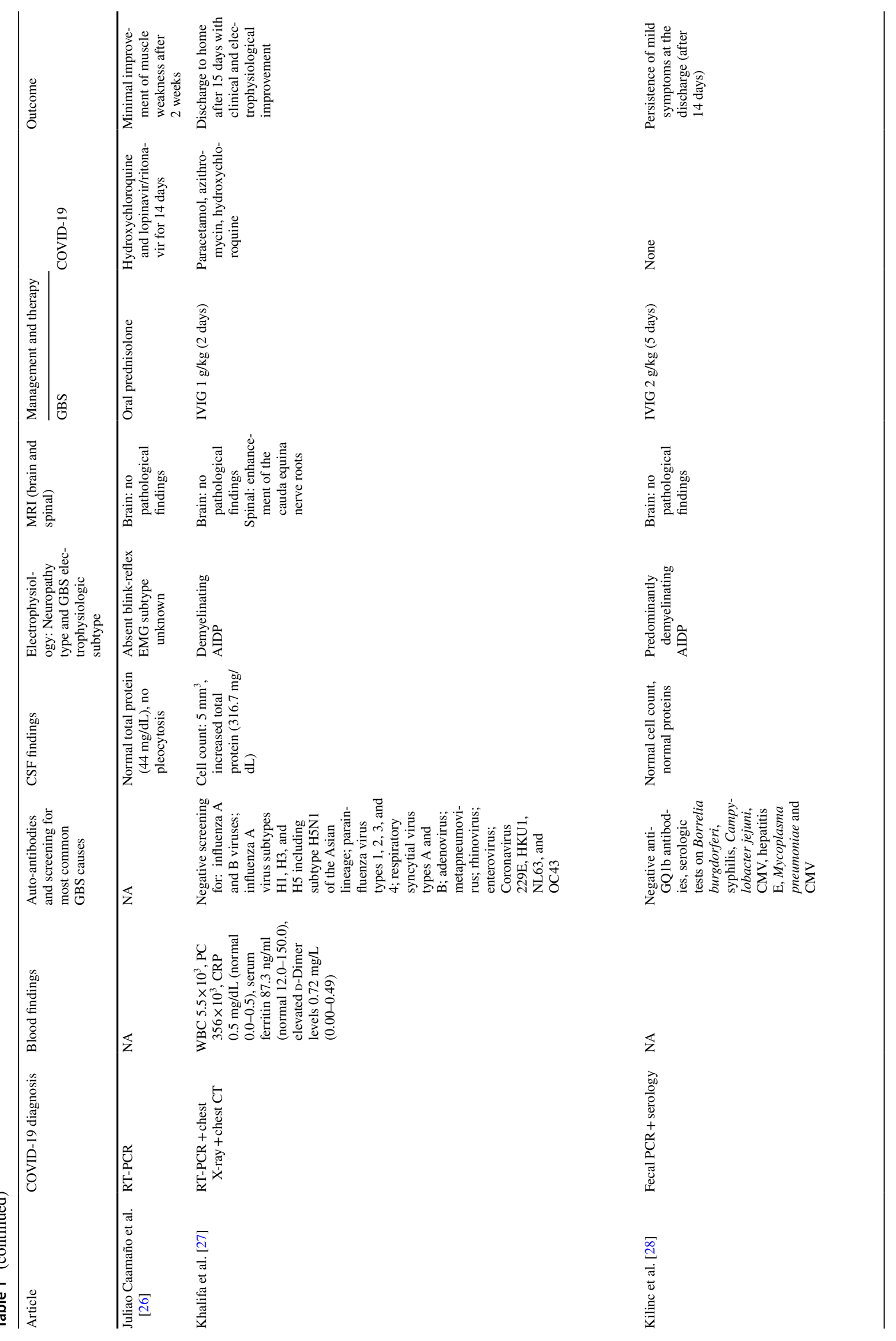




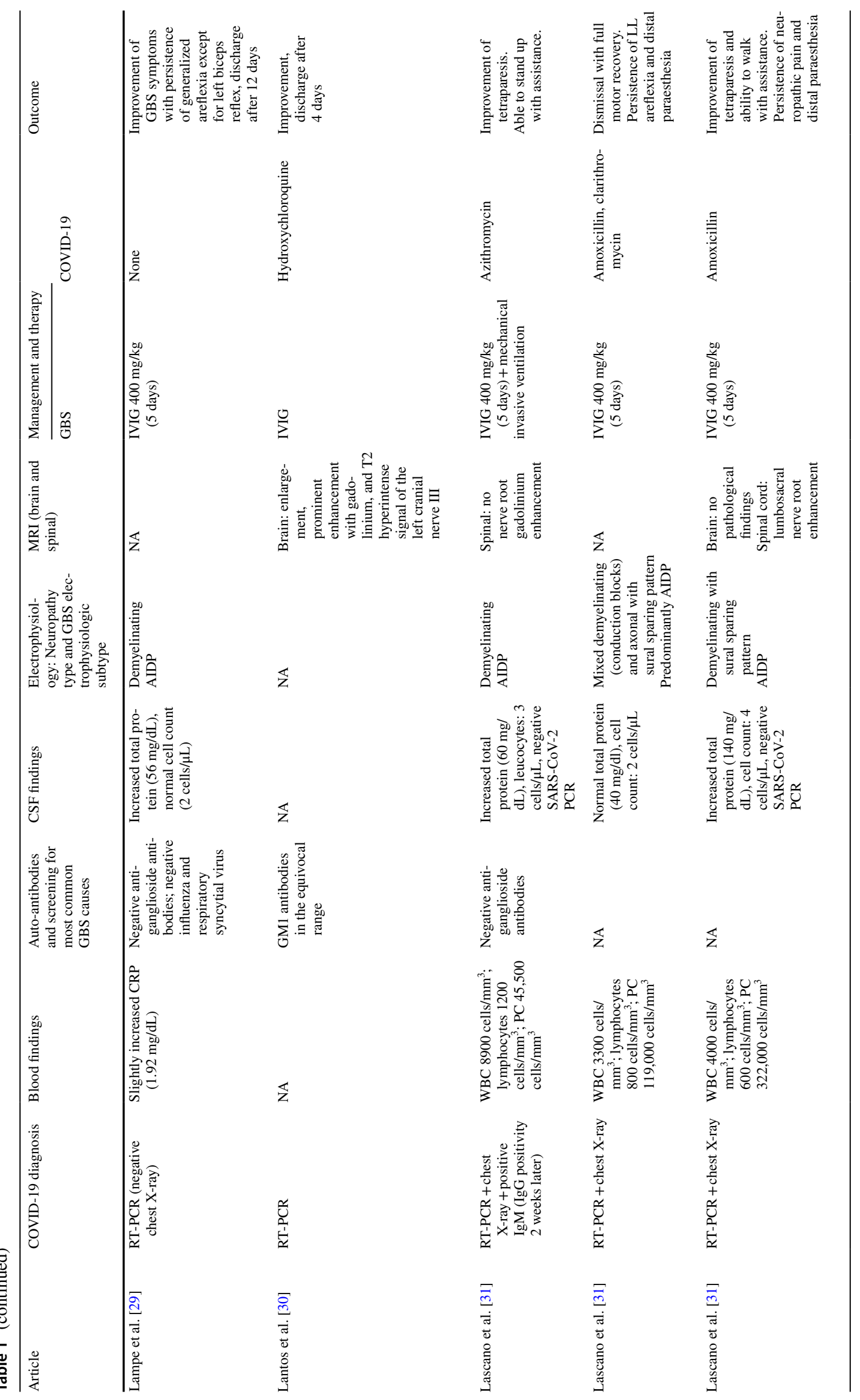




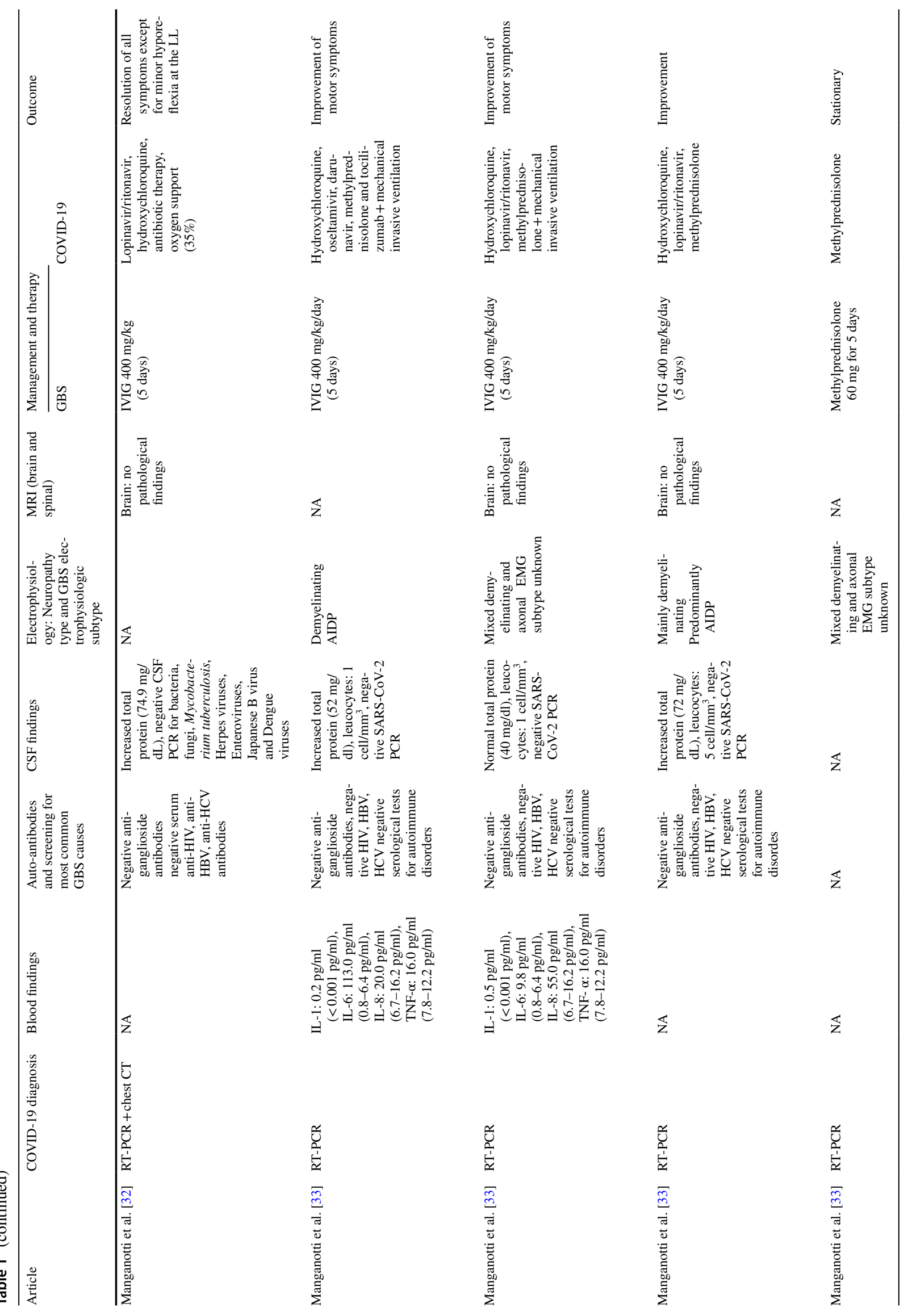




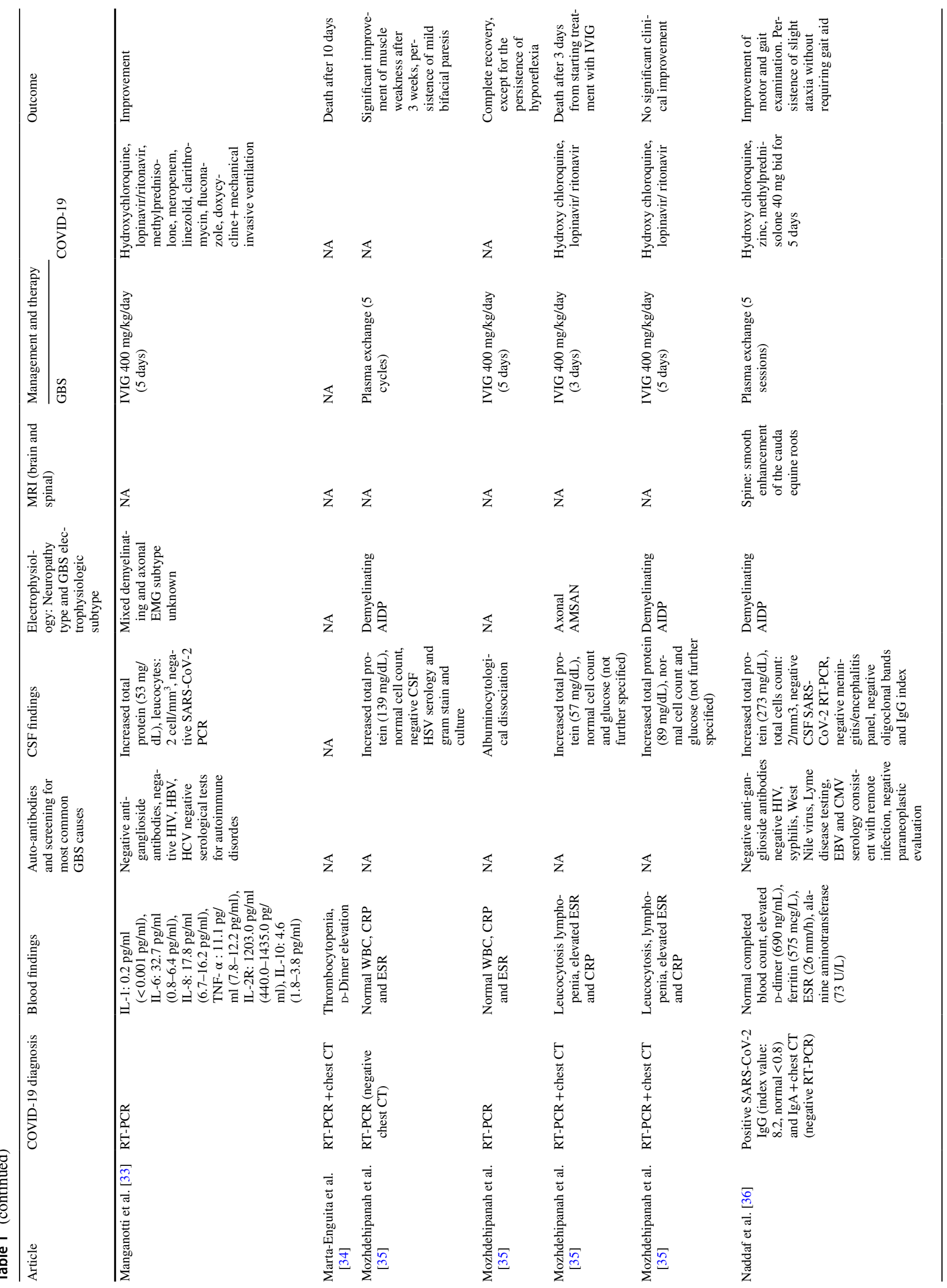




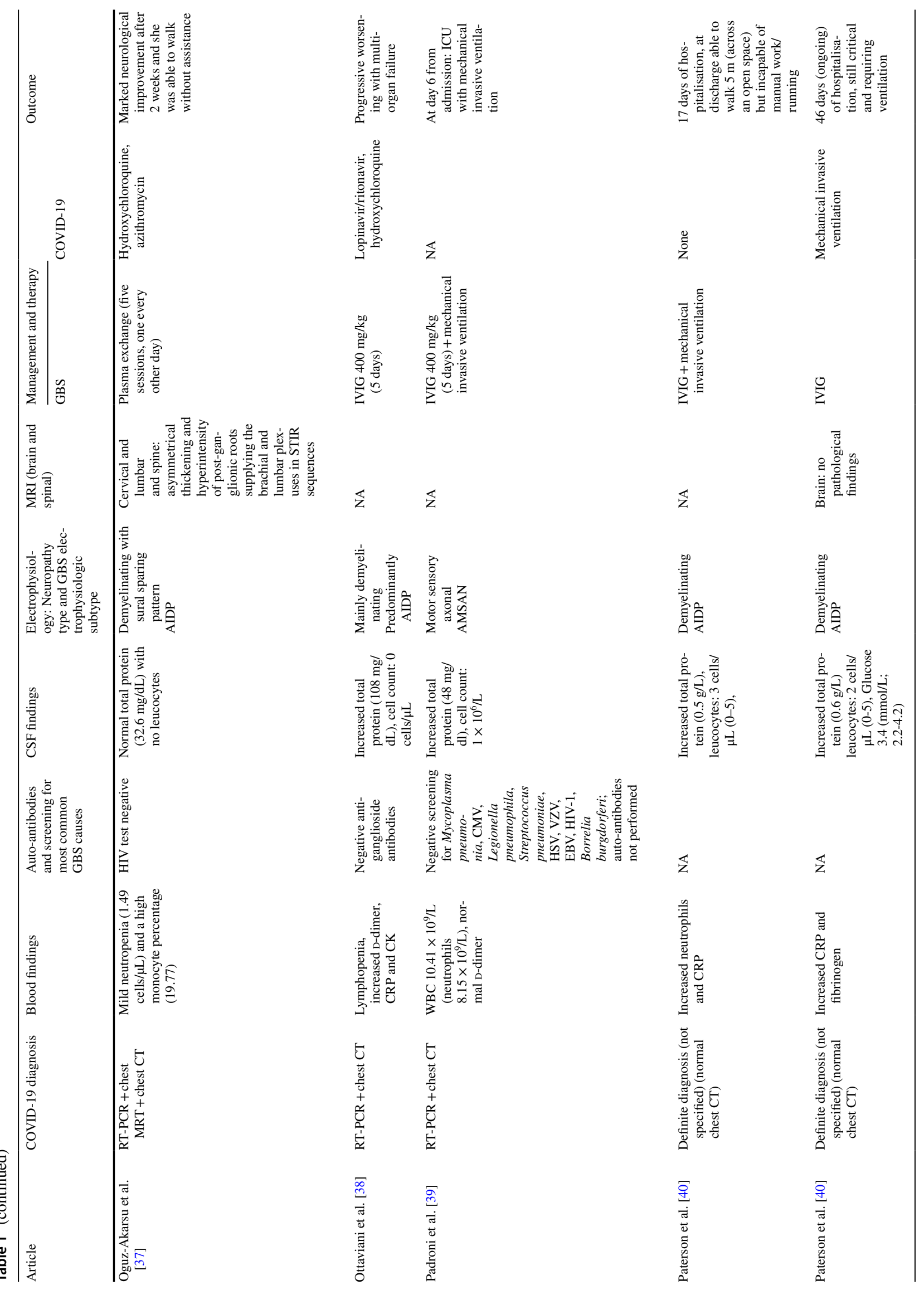




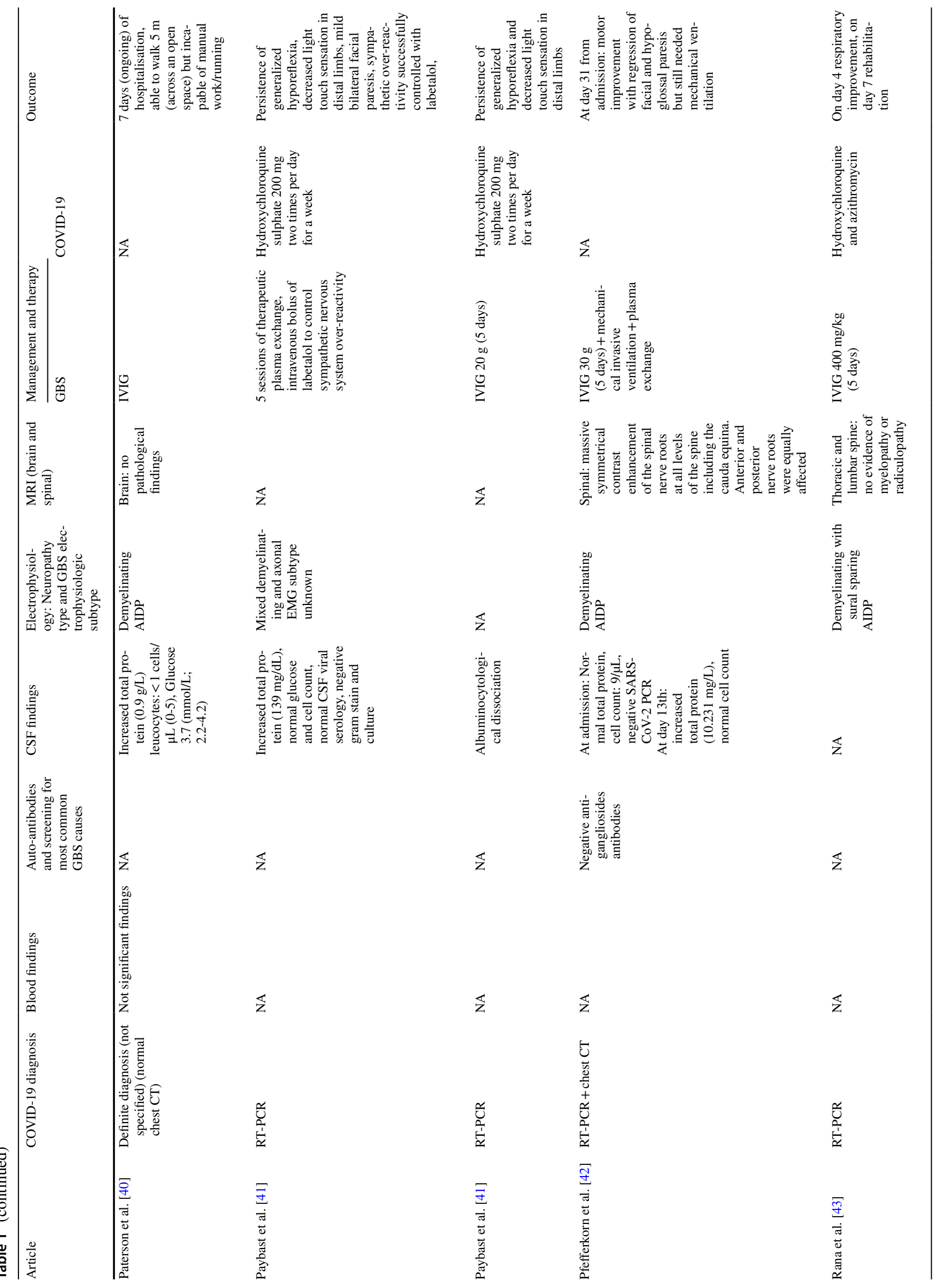




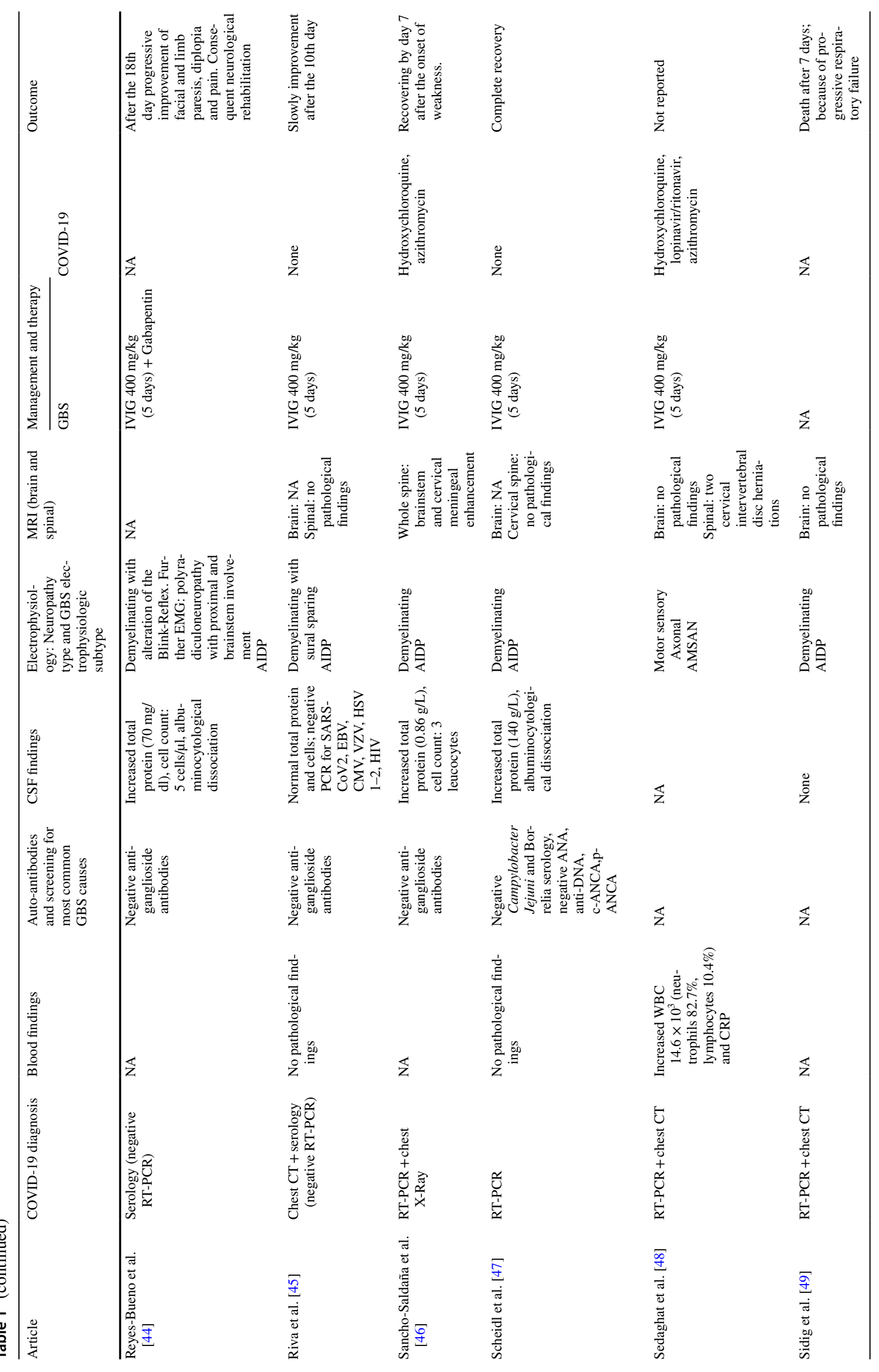




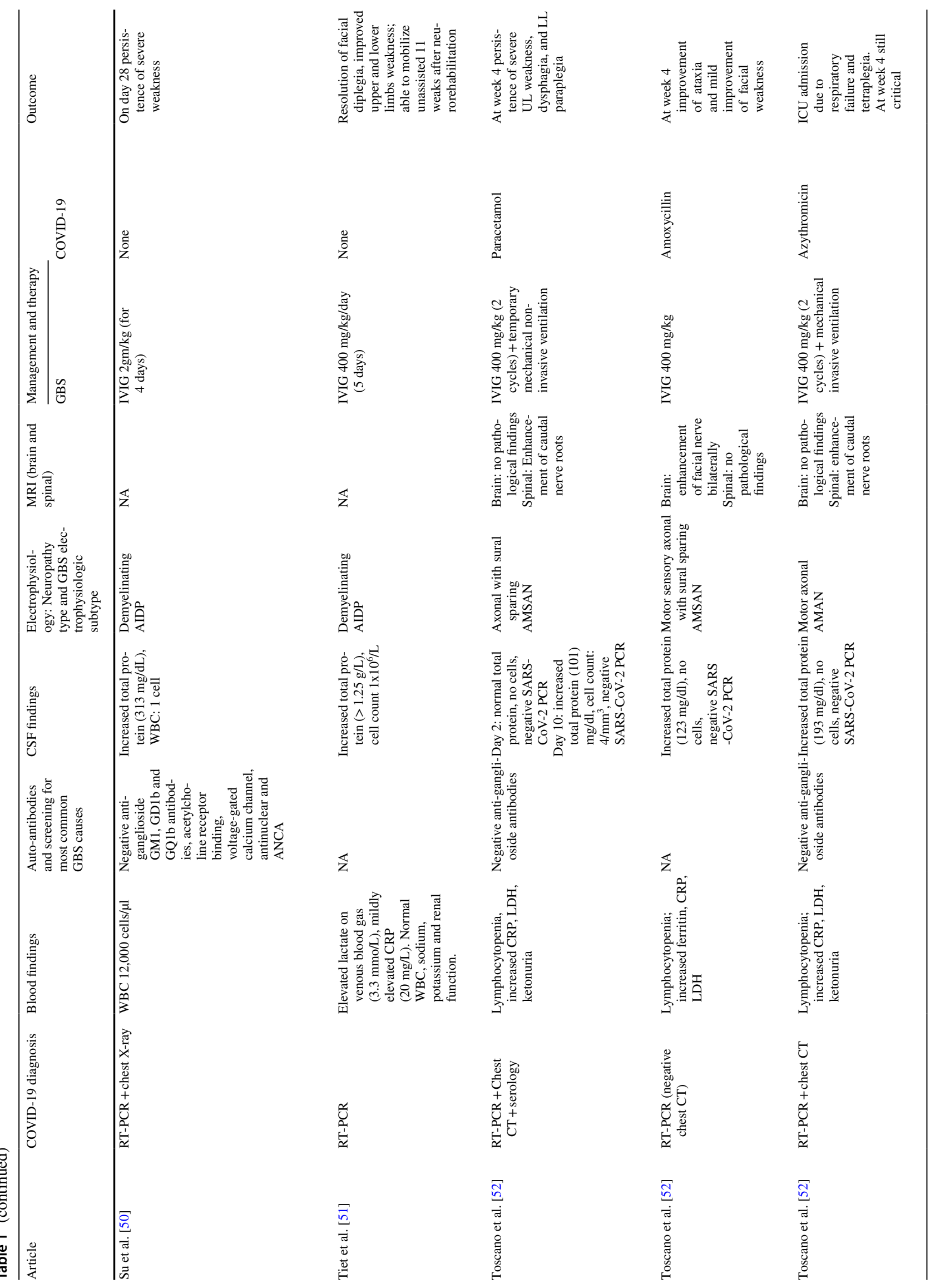




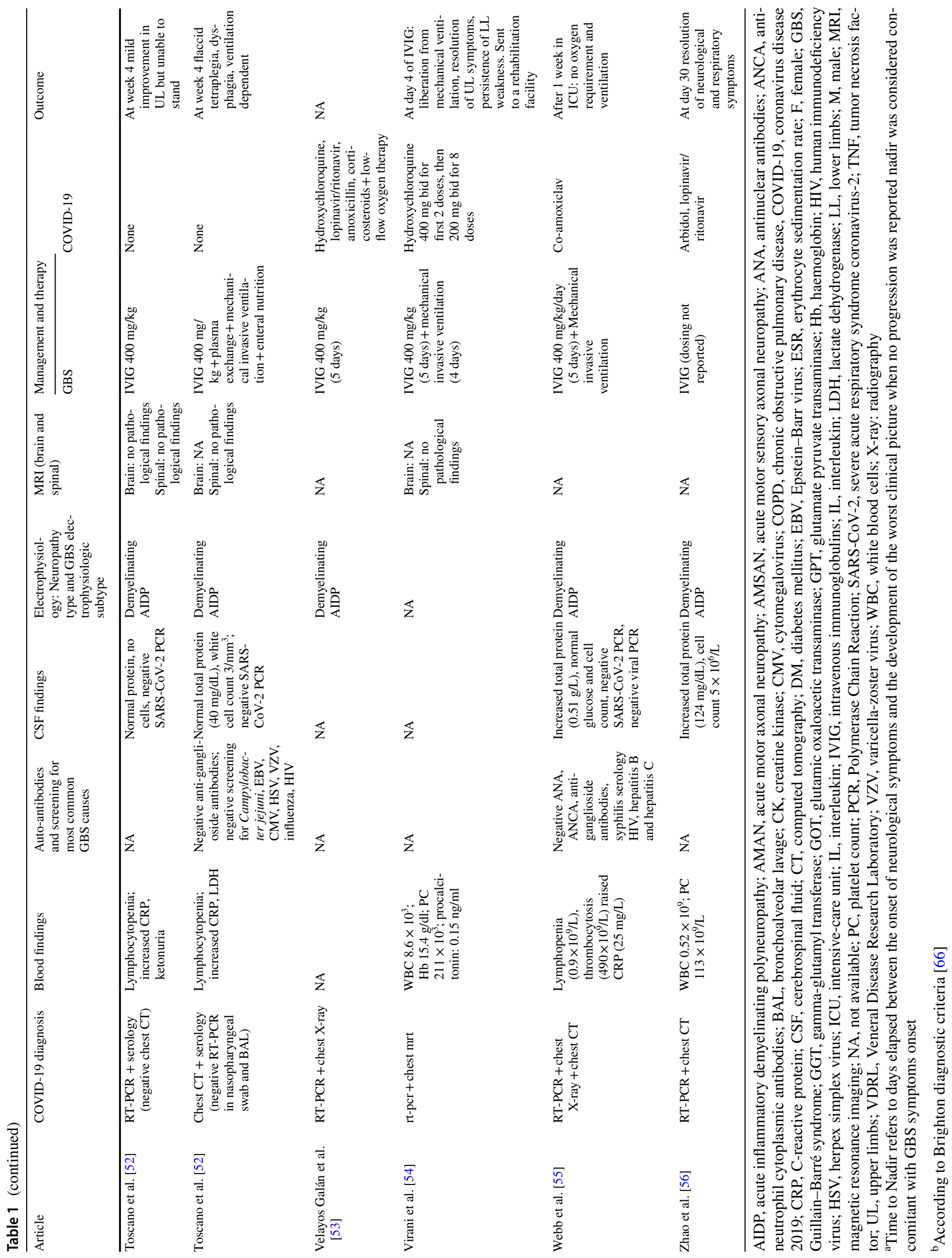


the notion of a prominent post-infectious immune-mediated mechanism. However, in this context, the massive release of cytokines in COVID-19 may also contribute to the amplification of the dysimmune process underlying GBS [76, 77]. In this regard, the increase of blood inflammatory markers (e.g., CRP, IL-6, TNF- $\alpha$, IL-1, etc.) in GBS tested cases may reinforce the hypothesis of a systemic inflammatory storm in COVID-19 [76, 77]. However, given the limited data, we could not perform an accurate analysis of the distribution and, eventually, prognostic value of inflammatory markers in COVID-19-associated GBS. Moreover, we cannot exclude that in cases with GBS developing before or together with COVID-19 symptoms, the disease might have progressed sub-clinically in the early phase to manifest afterwards with its typical systemic clinical picture. Indeed, two cases [10, 12], who tested positive for SARS-CoV-2, never developed COVID-19 respiratory or systemic symptoms and one of them showed an asymptomatic pneumonia at chest-CT [12]. However, only more extensive epidemiological and translational studies, with the aim to compare the characteristics of GBS associated or not with COVID-19, could clarify these issues.

In our population, most common clinical manifestations and distribution of clinical variants resemble those of classic GBS confirming the predominance of the sensorimotor syndrome compared to MFS and other rare variants [57-59, 66]. Similarly, the results of CSF analysis reflected typical neurochemical findings in non-COVID-19 GBS. In the latter, elevated CSF proteins and pleocytosis were described in about $50-80 \%[57,78]$ and $11-15 \%$ cases, respectively $[58,79,80]$, largely overlapping with the percentages in our cohort. In this regard, the mostly normal cell count, together with the absence of SARS-CoV-2 RNA in all tested CSF samples [6-9, 12-14, 16, 21-24, 31, 33, 36, 42, 44, 52, 55], makes the possibility of a direct invasion from SARS-CoV-2 into the nerve roots with intrathecal viral replication less probable. However, a possible bias might rely on the lack of systematic data concerning the latency between symptom onset and CSF sampling in COVID-19 GBS cases. On another issue, in a further case of MFS associated withCOVID-19, who came to our attention, we observed the absence of intrathecal synthesis of SARS-CoV-2 antibodies together with a massive increase of CSF phosphorylated neurofilament heavy chain $(\mathrm{pNfH})$ and serum neurofilament light chain (NfL) proteins, supporting the role of neurochemical markers as easily implementable tools for the detection of nervous system affection in COVID-19-related diseases [81, 82].

At variance with CSF findings, we found a discrepancy concerning MRI findings between classic GBS and COVID19-related GBS. Specifically, while most cases of the former group showed typically spinal root enhancement at MRI [83], in the latter group, in analogy with Zika-associated
GBS, the same finding was less frequently reported [84]. However, caution should be warranted in the interpretation of these results, given that MRI findings might have been underestimated, due to lack of a sufficient number of exams in the context of pandemic-imposed restrictions in the routine clinical setting.

Regarding the distribution of GBS electrophysiological variants, our analysis showed that COVID-19-associated GBS manifests prevalently with AIDP and, to a lesser extent, with AMSAN and AMAN, in line with classic GBS in Western countries $[66,85]$. Conversely, the observation of positive anti-GD1b antibodies in one COVID-19-related MFS patient and negative anti-ganglioside antibodies in other five cases appear in discordance with the high prevalence $(\approx 90 \%)$ of anti-GQ1b antibodies among non-COVID-19 MFS cases [86], and may suggest different immune-mediated mechanisms. However, these results could not be generalized until a wider population would be tested.

In analogy to classic GBS, approximately one-fifth of COVID-19-associated GBS subjects required mechanical ventilation during hospitalisation [87]. In this regard, cases with no improvement or unfavorable outcome showed, in comparison to those with a good prognosis, an older age, confirming similar findings both in classic GBS $[58,88]$ and in COVID-19 [89], and a slightly higher frequency (without reaching a statistical significance) of past or concurrent COVID-19 pneumonia. However, given the short follow-up time in most cases, we could not reach a definite conclusion on the impact of past or concurrent COVID-19 restrictive syndrome due to pneumonia on the prognosis of GBS patients. Future prospective studies are needed to clarify this issue. Moreover, given that also preceding diarrhea (mostly caused by Campylobacter Jejuni infection) is a strong negative prognostic factor in classic GBS [57, 88], further prospective studies are needed to compare the severity of GBS related to COVID-19 to that associated with C. jejuni. Finally, in the context of respiratory failure and ventilation associated with COVID-19, the differential diagnosis should always take into consideration critical illness neuropathy and myopathy, which tend to develop later during the critical course [90]. Despite these findings, approximately one-third of COVID-19-related GBS patients showed no clinical and/ or radiological evidence of pneumonia, providing evidence that GBS may also develop in the context of a paucisymptomatic or even asymptomatic COVID-19. However, given that among the GBS population only two asymptomatic COVID-19 patients were reported to date, we may speculate that, in most cases, a certain degree of lung injury (even minimal) or at least hematic dissemination (e.g., fever underlying significant viral load) is necessary to trigger the immuno-mediated process through lymphocytic recognition of self-antigens or molecular mimicry. 


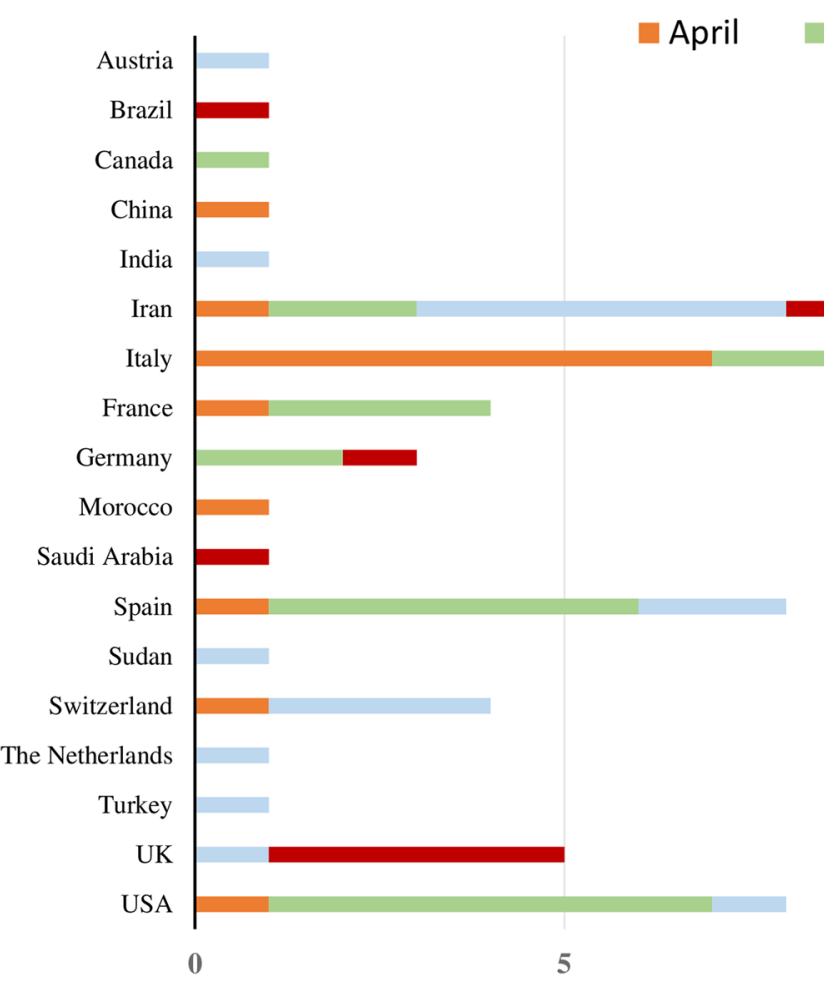

Fig. 1 Temporal and spatial distribution of reported cases with COVID-19-associated Guillain-Barré syndrome in literature from 1st January until 20th July 2020. The $x$-axis shows the number of described patients. The $y$-axis illustrates the countries of provenience

Major strengths of our review are the inclusion of a high number of patients, together with an in-depth analysis of the clinical and diagnostic features of COVID-19-associated GBS. We are aware that selection bias might have occurred, given that most reported cases to date have been described mostly in Europe (47 out of 73) and during COVID-19 highest spreading. Therefore, future extensive epidemiological studies are necessary to ascertain the nature of the association between COVID-19 and GBS (causal or coincidental). Moreover, we cannot exclude the possibility that at least some of the cases represent instances of CIDP, given the frequent absence of a follow-up longer than 2 months. On another issue, the low but possible evidence of an epidemiological link between vaccines and GBS development [57, 58] should aware the clinicians of the possible occurrence of GBS after COVID-19 vaccination in the long-term future.

In conclusion, based on the systematic review of 73 cases, we showed that the clinical picture of COVID-19-associated GBS seems to resemble that of classic GBS or Zikaassociated GBS. Moreover, the chronological evolution, the response to IVIG, and the absence of SARS-CoV-2 RNA in CSF may suggest a prominent post-infectious immunemediated mechanism rather than a para-infectious one. Although most cases were symptomatic for COVID-19, the preliminary report of a few patients without respiratory or systemic symptoms raises a significant healthcare issue, namely the importance of SARS-CoV-2 testing in all patients with suspected GBS during the pandemic, with the aim to provide an eventual rapid case isolation. Nevertheless, only further analyses on more comprehensive cohorts could help in clarifying better all these issues.

Acknowledgements Open Access funding provided by Projekt DEAL. This work was in part supported by a COVID-19 grant from the state Baden-Württemberg.

Authors' contributions Conceptualization: all authors; methodology, formal analysis, and investigation: Samir Abu-Rumeileh, Ahmed Abdelhak, and Matteo Foschi; writing - original draft preparation: all authors; figure preparation: Matteo Foschi; writing-review and editing: all authors; supervision: Markus Otto and Hayrettin Tumani.

\section{Compliance with ethical standards}

Conflicts of interest The authors declare that they have no conflict of interest related to the content of this article.

Ethical standard For the present study, no authorization to an Ethics Committee was asked, because the original reports, nor this work, provided any personal information of the patients. 
Open Access This article is licensed under a Creative Commons Attribution 4.0 International License, which permits use, sharing, adaptation, distribution and reproduction in any medium or format, as long as you give appropriate credit to the original author(s) and the source, provide a link to the Creative Commons licence, and indicate if changes were made. The images or other third party material in this article are included in the article's Creative Commons licence, unless indicated otherwise in a credit line to the material. If material is not included in the article's Creative Commons licence and your intended use is not permitted by statutory regulation or exceeds the permitted use, you will need to obtain permission directly from the copyright holder. To view a copy of this licence, visit http://creativecommons.org/licenses/by/4.0/.

\section{References}

1. WHO (2020) Coronavirus disease 2019 (COVID-19). https:// www.who.int/emergencies/diseases/novel-coronavirus-2019. Accessed 20 July 2002

2. Mao L, Jin H, Wang M et al (2020) Neurologic manifestations of hospitalized patients with coronavirus disease 2019 in Wuhan, China. JAMA Neurol. https://doi.org/10.1001/jamaneurol .2020 .1127

3. Montalvan V, Lee J, Bueso T et al (2020) Neurological manifestations of COVID-19 and other coronavirus infections: a systematic review. Clin Neurol Neurosurg 194:105921. https://doi. org/10.1016/j.clineuro.2020.105921

4. Koralnik IJ, Tyler KL (2020) COVID-19: a global threat to the nervous system. Ann Neurol. https://doi.org/10.1002/ana.25807

5. Agosti E, Giorgianni A, D'Amore F et al (2020) Is Guillain-Barrè syndrome triggered by SARS-CoV-2? Case report and literature review. Neurol Sci. https://doi.org/10.1007/s10072-020-04553-9

6. Alberti P, Beretta S, Piatti M et al (2020) Guillain-Barré syndrome related to COVID-19 infection. Neurol Neuroimmunol Neuroinflamm 7(4):e741. https://doi.org/10.1212/NXI.000000000000074 1

7. Arnaud S, Budowski C, Ng Wing Tin S et al (2020) Post SARSCoV-2 Guillain-Barré syndrome. Clin Neurophysiol 131(7):16521654. https://doi.org/10.1016/j.clinph.2020.05.003

8. Assini A, Benedetti L, Di Maio S et al (2020) New clinical manifestation of COVID-19 related Guillain-Barré syndrome highly responsive to intravenous immunoglobulins: two Italian cases. Neurol Sci. https://doi.org/10.1007/s10072-020-04484-5

9. Bigaut K, Mallaret M, Baloglu S et al (2020) Guillain-Barré syndrome related to SARS-CoV-2 infection. Neurol Neuroimmunol Neuroinflamm 7(5):e785. https://doi.org/10.1212/nxi.0000000000 000785

10. Bracaglia M, Naldi I, Govoni A et al (2020) Acute inflammatory demyelinating polyneuritis in association with an asymptomatic infection by SARS-CoV-2. J Neurol. https://doi.org/10.1007/ s00415-020-10014-2

11. Camdessanche JP, Morel J, Pozzetto B et al (2020) COVID-19 may induce Guillain-Barré syndrome. Rev Neurol 176(6):516518. https://doi.org/10.1016/j.neurol.2020.04.003

12. Chan JL, Ebadi H, Sarna JR (2020) Guillain-Barré syndrome with facial diplegia related to SARS-CoV-2 infection. Can J Neurol Sci. https://doi.org/10.1017/cjn.2020.106

13. Chan M, Han SC, Kelly S et al (2020) A case series of GuillainBarré Syndrome following Covid-19 infection in New York. Neurol Clin Pract. https://doi.org/10.1212/CPJ.0000000000000880

14. Coen M, Jeanson G, Culebras Almeida LA et al (2020) GuillainBarré syndrome as a complication of SARS-CoV-2 infection. Brain Behav Immun. https://doi.org/10.1016/j.bbi.2020.04.074

15. Ebrahimzadeh SA, Ghoreishi A, Rahimian N (2020) GuillainBarré Syndrome associated with the coronavirus disease 2019
(COVID-19). Neurol Clin Pract. https://doi.org/10.1212/ CPJ.0000000000000879

16. El Otmani H, El Moutawakil B, Rafai MA et al (2020) Covid-19 and Guillain-Barré syndrome: more than a coincidence! Rev Neurol 176(6):518-519. https://doi.org/10.1016/j.neurol.2020.04.007

17. Esteban Molina A, Mata Martínez M, Sánchez Chueca $P$ et al (2020) Guillain-Barré Syndrome associated with SARS-CoV-2 infection. Med Intensiva. https://doi.org/10.1016/j.medin .2020 .04 .015

18. Farzi MA, Ayromlou H, Jahanbakhsh N et al (2020) GuillainBarré syndrome in a patient infected with SARS-CoV-2, a case report. J Neuroimmunol 346:577294. https://doi.org/10.1016/j. jneuroim.2020.577294

19. Fernández-Domínguez J, Ameijide-Sanluis E, García-Cabo C et al (2020) Miller-Fisher-like syndrome related to SARS-CoV-2 infection (COVID 19). J Neurol. https://doi.org/10.1007/s0041 5-020-09912-2

20. Finsterer J, Scorza FA, Ghosh R (2020) COVID-19 polyradiculitis in 24 patients without SARS-CoV-2 in the cerebro-spinal fluid. $\mathrm{J}$ Med Virol. https://doi.org/10.1002/jmv.26121

21. Frank CHM, Almeida TVR, Marques EA et al (2020) GuillainBarré Syndrome associated with SARS-CoV-2 infection in a pediatric patient. J Trop Pediatr. https://doi.org/10.1093/tropej/fmaa0 44

22. Gigli GL, Bax F, Marini A et al (2020) Guillain-Barré syndrome in the COVID-19 era: just an occasional cluster? J Neurol. https ://doi.org/10.1007/s00415-020-09911-3

23. Gutiérrez-Ortiz C, Méndez A, Rodrigo-Rey S et al (2020) Miller Fisher Syndrome and polyneuritis cranialis in COVID-19. Neurology. https://doi.org/10.1212/WNL.0000000000009619

24. Helbok R, Beer R, Löscher W et al (2020) Guillain-Barré syndrome in a patient with antibodies against SARS-COV-2. Eur J Neurol. https://doi.org/10.1111/ene.14388

25. Hutchins KL, Jansen JH, Comer AD et al (2020) COVID19-associated bifacial weakness with paresthesia subtype of Guillain-Barré syndrome. AJNR Am J Neuroradiol. https://doi. org/10.3174/ajnr.A6654

26. Juliao Caamaño DS, Alonso Beato R (2020) Facial diplegia, a possible atypical variant of Guillain-Barré Syndrome as a rare neurological complication of SARS-CoV-2. J Clin Neurosci. https ://doi.org/10.1016/j.jocn.2020.05.016

27. Khalifa M, Zakaria F, Ragab Y et al (2020) Guillain-Barre syndrome associated with SARS-CoV-2 Detection and a COVID19 infection in a child. J Pediatric Infect Dis Soc. https://doi. org/10.1093/jpids/piaa086

28. Kilinc D, van de Pasch S, Doets AY et al (2020) Guillain-Barré syndrome after SARS-CoV-2 infection. Eur J Neurol. https://doi. org/10.1111/ene. 14398

29. Lampe A, Winschel A, Lang C et al (2020) Guillain-Barré syndrome and SARS-CoV-2. Neurol Res Pract 2:19. https://doi. org/10.1186/s42466-020-00066-0

30. Lantos JE, Strauss SB, Lin E (2020) COVID-19-associated Miller Fisher Syndrome: MRI findings. AJNR Am J Neuroradiol. https ://doi.org/10.3174/ajnr.A6609

31. Lascano AM, Epiney JB, Coen M et al (2020) SARS-CoV-2 and Guillain-Barré syndrome: AIDP variant with favorable outcome. Eur J Neurol. https://doi.org/10.1111/ene.14368

32. Manganotti P, Pesavento V et al (2020) Miller Fisher syndrome diagnosis and treatment in a patient with SARS-CoV-2. J Neurovirol. https://doi.org/10.1007/s13365-020-00858-9

33. Manganotti P, Bellavita G, D'Acunto L et al (2020) Clinical neurophysiology and cerebrospinal liquor analysis to detect Guillain Barré syndrome and polyneuritis cranialis in COVID-19 patients: a case series. J Med Virol. https://doi.org/10.1002/jmv.26289

34. Marta-Enguita J, Rubio-Baines I, Gastón-Zubimendi I (2020) Fatal Guillain-Barre syndrome after infection with SARS-CoV-2. 
Síndrome de Guillain-Barré fatal tras infección por el virus SARSCoV-2. Neurologia 35(4):265-267. https://doi.org/10.1016/j. nrl.2020.04.004

35. Mozhdehipanah H, Paybast S, Gorji R (2020) Guillain-Barré syndrome as a neurological complication of COVID-19 infection: a case series and review of the literature. Int Clin Neurosci J 7(3):156-161

36. Naddaf E, Laughlin RS, Klein CJ et al (2020) Guillain-Barre syndrome in a patient with evidence of recent SARS-CoV-2 infection. Mayo Clin Proc. https://doi.org/10.1016/j.mayocp.2020.05.029

37. Oguz-Akarsu E, Ozpar R, Mirzayev H et al (2020) Guillain-Barré syndrome in a patient with minimal symptoms of COVID-19 infection. Muscle Nerve. https://doi.org/10.1002/mus.26992

38. Ottaviani D, Boso F, Tranquillini E et al (2020) Early GuillainBarré syndrome in coronavirus disease 2019 (COVID-19): a case report from an Italian COVID-hospital. Neurol Sci 41(6):13511354. https://doi.org/10.1007/s10072-020-04449-8

39. Padroni M, Mastrangelo V, Asioli GM et al (2020) Guillain-Barré syndrome following COVID-19: new infection, old complication? J Neurol. https://doi.org/10.1007/s00415-020-09849-6

40. Paterson RW, Brown RL, Benjamin L et al (2020) The emerging spectrum of COVID-19 neurology: clinical, radiological and laboratory findings. Brain. https://doi.org/10.1093/brain/ awaa240

41. Paybast S, Gorji R, Mavandadi S (2020) Guillain-Barré syndrome as a neurological complication of novel COVID-19 infection: a case report and review of the literature. Neurologist 25(4):101103. https://doi.org/10.1097/NRL.0000000000000291

42. Pfefferkorn T, Dabitz R, von Wernitz-Keibel T et al (2020) Acute polyradiculoneuritis with locked-in syndrome in a patient with Covid-19. J Neurol. https://doi.org/10.1007/s00415-020-09897-y

43. Rana S, Lima AA, Chandra R et al (2020) Novel coronavirus (COVID-19)-associated Guillain-Barré syndrome: case report. J Clin Neuromuscul Dis 21(4):240-242. https://doi.org/10.1097/ CND.0000000000000309

44. Reyes-Bueno JA, García-Trujillo L, Urbaneja P et al (2020) Miller-Fisher syndrome after SARS-CoV-2 infection. Eur J Neurol. https://doi.org/10.1111/ene.14383

45. Riva N, Russo T, Falzone YM et al (2020) Post-infectious Guillain-Barré syndrome related to SARS-CoV-2 infection: a case report. J Neurol. https://doi.org/10.1007/s00415-020-09907-z

46. Sancho-Saldaña A, Lambea-Gil Á, Liesa JLC et al (2020) Guillain-Barré syndrome associated with leptomeningeal enhancement following SARS-CoV-2 infection. Clin Med. https://doi. org/10.7861/clinmed.2020-0213

47. Scheidl E, Canseco DD, Hadji-Naumov A et al (2020) GuillainBarré syndrome during SARS-CoV-2 pandemic: a case report and review of recent literature. J Peripher Nerv Syst. https://doi. org/10.1111/jns. 12382

48. Sedaghat Z, Karimi N (2020) Guillain Barre syndrome associated with COVID-19 infection: a case report. J Clin Neurosci 76:233-235. https://doi.org/10.1016/j.jocn.2020.04.062

49. Sidig A, Abbasher K, Abbasher $\mathrm{H}$ et al. (2020). COVID-19 and Guillain-Barre syndrome case report. J Neurol Neurobiol 6(3)

50. Su XW, Palka SV, Rao RR et al (2020) SARS-CoV-2-associated Guillain-Barré syndrome with dysautonomia. Muscle Nerve. https ://doi.org/10.1002/mus.26988

51. Tiet MY, AlShaikh N (2020) Guillain-Barré syndrome associated with COVID-19 infection: a case from the UK. BMJ Case Rep 13(7):e236536

52. Toscano G, Palmerini F, Ravaglia S et al (2020) Guillain-Barré syndrome associated with SARS-CoV-2. N Engl J Med. https:// doi.org/10.1056/nejmc2009191

53. Velayos Galán A, Del Saz Saucedo P, Peinado Postigo F et al (2020) Guillain-Barré syndrome associated with SARSCoV-2 infection. Síndrome de Guillain-Barré asociado a infección por SARS-CoV-2. Neurologia 35(4):268-269. https:// doi.org/10.1016/j.nrl.2020.04.007

54. Virani A, Rabold E, Hanson T et al (2020) Guillain-Barré Syndrome associated with SARS-CoV-2 infection. IDCases 20:e00771. https://doi.org/10.1016/j.idcr.2020.e00771

55. Webb S, Wallace VC, Martin-Lopez D et al (2020) GuillainBarré syndrome following COVID-19: a newly emerging postinfectious complication. BMJ Case Rep 13(6):e236182. https:// doi.org/10.1136/bcr-2020-236182

56. Zhao H, Shen D, Zhou H et al (2020) Guillain-Barré syndrome associated with SARS-CoV-2 infection: causality or coincidence? Lancet Neurol 19(5):383-384. https://doi.org/10.1016/S1474 $-4422(20) 30109-5$

57. Leonhard SE, Mandarakas MR, Gondim FAA et al (2019) Diagnosis and management of Guillain-Barré syndrome in ten steps. Nat Rev Neurol 15(11):671-683. https://doi.org/10.1038/s4158 2-019-0250-9

58. Willison HJ, Jacobs BC, van Doorn PA (2016) Guillain-Barré syndrome. Lancet 388(10045):717-727. https://doi.org/10.1016/ S0140-6736(16)00339-1

59. Kieseier BC, Mathey EK, Sommer C et al (2018) Immune-mediated neuropathies. Nat Rev Dis Primers 4:31

60. Wakerley BR, Yuki N (2015) Polyneuritis cranialis-subtype of Guillain-Barré syndrome? Nat Rev Neurol 11(11):664. https:// doi.org/10.1038/nrneurol.2015.115

61. Uncini A, Kuwabara S (2018) The electrodiagnosis of GuillainBarré syndrome subtypes: where do we stand? Clin Neurophysiol 129(12):2586-2593. https://doi.org/10.1016/j.clinph.2018.09.025

62. Costello F, Dalakas MC (2020) Cranial Neuropathies and COVID19: neurotropism and Autoimmunity. Neurology. https://doi. org/10.1212/WNL.0000000000009921

63. Kim JE, Heo JH, Kim HO et al (2010) Neurological complications during treatment of Middle East Respiratory Syndrome. J Clin Neurol 13(3):227-233

64. Zhou Z, Kang H, Li S et al (2020) Understanding the neurotropic characteristics of SARS-CoV-2: from neurological manifestations of COVID-19 to potential neurotropic mechanisms. J Neurol. https ://doi.org/10.1007/s00415-020-09929-7

65. Grant MJ, Booth A (2009) A typology of reviews: an analysis of 14 review types and associated methodologies. Health Info Libr J 26:91-108

66. Fokke C, van den Berg B, Drenthen J et al (2014) Diagnosis of Guillain-Barre syndrome and validation of Brighton criteria. Brain 137(Pt 1):33-43

67. Desforges M, Le Coupanec A, Brison E et al (2014) Neuroinvasive and neurotropic human respiratory coronaviruses: potential neurovirulent agents in humans. Adv Exp Med Biol 807:75-96. https://doi.org/10.1007/978-81-322-1777-0_6

68. Dalakas MC (2020) Guillain-Barré syndrome: the first documented COVID-19-triggered autoimmune neurologic disease: More to come with myositis in the offing. Neurol Neuroimmunol Neuroinflamm 7(5):e781

69. Wang L, Shen Y, Li M et al (2020) Clinical manifestations and evidence of neurological involvement in 2019 novel coronavirus SARS-CoV-2: a systematic review and meta-analysis. J Neurol. https://doi.org/10.1007/s00415-020-09974-2

70. Guan WJ, Ni ZY, Hu Y et al (2020) Clinical characteristics of coronavirus disease 2019 in China. N Engl J Med 382(18):17081720. https://doi.org/10.1056/NEJMoa2002032

71. Jin JM, Bai P, He W et al (2020) Gender differences in patients with COVID-19: focus on severity and mortality. Front Public Health 8:152. https://doi.org/10.3389/fpubh.2020.00152

72. Dirlikov E, Major CG, Medina NA et al (2018) Clinical features of Guillain-Barré syndrome with vs without zika virus infection, Puerto Rico, 2016. JAMA Neurol 75(9):1089-1097. https://doi. org/10.1001/jamaneurol.2018.1058 
73. ECDC (2020) https://covid19-surveillance-report.ecdc.europa.eu, Accessed 20 July 2002

74. WHO (2020) https://www.who.int/emergencies/diseases/novel -coronavirus-2019/situation-reports/, Accessed 20 July 2020

75. Parra B, Lizarazo J, Jiménez-Arango JA et al (2016) GuillainBarré Syndrome Associated with Zika Virus Infection in Colombia. N Engl J Med 375(16):1513-1523

76. Balcioglu YH, Yesilkaya UH, Gokcay H et al (2020) May the central nervous system be fogged by the cytokine storm in COVID-19?: an Appraisal. J Neuroimmune Pharmacol. https:// doi.org/10.1007/s11481-020-09932-9

77. Costela-Ruiz VJ, Illescas-Montes R, Puerta-Puerta JM et al (2020) SARS-CoV-2 infection: the role of cytokines in COVID-19 disease. Cytokine Growth Factor Rev. https://doi.org/10.1016/j.cytog fr.2020.06.001

78. Tumani H, Brettschneider J (2012) Biochemical markers of autoimmune diseases of the nervous system. Curr Pharm Des 18(29):4556-4563. https://doi.org/10.2174/138161212802502143

79. Van der Meché FG, Van Doorn PA, Meulstee J et al (2001) GBS-consensus group of the Dutch Neuromuscular Research Support Centre. Diagnostic and classification criteria for the Guillain-Barré syndrome. Eur Neurol 45(3):133-139. https://doi. org/10.1159/000052111

80. Brettschneider J, Petzold A, Süssmuth S et al (2009) CSF biomarkers in GBS-where do we stand? J Neurol 256(1):3-12

81. Senel M, Abu-Rumeileh S, Michel D et al (2020) Miller-Fisher syndrome after COVID-19: neurochemical markers as an early sign of nervous system involvement. Eur J Neurol. https://doi. org/10.1111/ene.14473

82. Ameres M, Brandstetter S, Toncheva AA et al (2020) Association of neuronal injury blood marker neurofilament light chain with mild-to-moderate COVID-19. J Neurol. https://doi.org/10.1007/ s00415-020-10050-y
83. Berciano J, Sedano MJ, Pelayo-Negro AL et al (2017) Proximal nerve lesions in early Guillain-Barré syndrome: implications for pathogenesis and disease classification. J Neurol 264(2):221-236. https://doi.org/10.1007/s00415-016-8204-2

84. Watrin L, Ghawché F, Larre P et al (2016) Guillain-Barré Syndrome (42 cases) occurring during a zika virus outbreak in French Polynesia. Medicine 95(14):e3257. https://doi.org/10.1097/ MD.0000000000003257

85. Arcila-Londono X, Lewis RA (2020) Guillain-Barré syndrome. Semin Neurol 32(3):179-186. https://doi. org/10.1055/s-0032-1329196

86. Yoshikawa K, Kuwahara M, Morikawa M et al (2018) Varied antibody reactivities and clinical relevance in anti-GQ1b antibodyrelated diseases. Neurol Neuroimmunol Neuroinflamm 5(6): e501

87. Walgaard C, Lingsma HF, Ruts L et al (2010) Prediction of respiratory insufficiency in Guillain-Barré syndrome. Ann Neurol 67(6):781-787. https://doi.org/10.1002/ana.21976

88. van Koningsveld R, Steyerberg EW, Hughes RA et al (2007) A clinical prognostic scoring system for Guillain-Barré syndrome. Lancet Neurol 6(7):589-594. https://doi.org/10.1016/S1474 $-4422(07) 70130-8$

89. Liu Y, Mao B, Liang S et al (2020) Association between age and clinical characteristics and outcomes of COVID-19. Eur Respir J 55(5):2001112. https://doi.org/10.1183/13993003.01112-2020

90. Zink W, Kollmar R, Schwab S (2009) Critical illness polyneuropathy and myopathy in the intensive care unit. Nat Rev Neurol 5(7):372-379. https://doi.org/10.1038/nrneurol.2009.75 